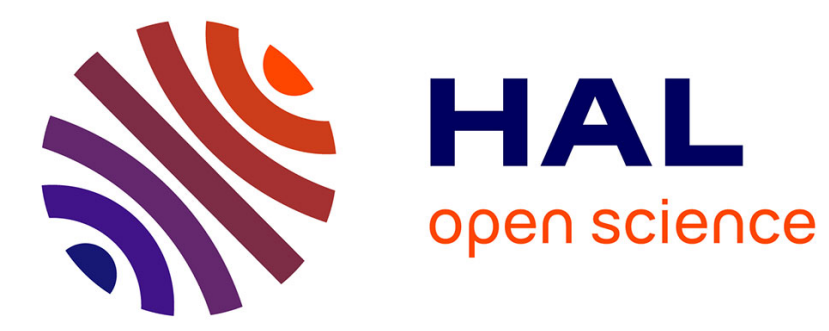

\title{
TEMPO-mediated oxidation of polysaccharides: An ongoing story
}

Guillaume Pierre, Carlo Punta, Cédric Delattre, Lucio Melone, Pascal

Dubessay, Andrea Fiorati, Nadia Pastori, Yves M. Galante, Philippe Michaud

\section{- To cite this version:}

Guillaume Pierre, Carlo Punta, Cédric Delattre, Lucio Melone, Pascal Dubessay, et al.. TEMPOmediated oxidation of polysaccharides: An ongoing story. Carbohydrate Polymers, 2017, 165, pp.71 85. 10.1016/j.carbpol.2017.02.028 . hal-01657840

\author{
HAL Id: hal-01657840 \\ https://hal.uca.fr/hal-01657840
}

Submitted on 28 Feb 2019

HAL is a multi-disciplinary open access archive for the deposit and dissemination of scientific research documents, whether they are published or not. The documents may come from teaching and research institutions in France or abroad, or from public or private research centers.
L'archive ouverte pluridisciplinaire HAL, est destinée au dépôt et à la diffusion de documents scientifiques de niveau recherche, publiés ou non, émanant des établissements d'enseignement et de recherche français ou étrangers, des laboratoires publics ou privés.

\section{(ㄷ)(1) $\$$}

Distributed under a Creative Commons Attribution - NonCommerciall 4.0 International 


\title{
TEMPO-mediated oxidation of polysaccharides: An ongoing story
}

\author{
Guillaume Pierre ${ }^{a, b, *}$, Carlo Punta $^{c}$, Cédric Delattre $^{\mathrm{a}, \mathrm{b}}$, Lucio Melone ${ }^{\mathrm{c}, \mathrm{d}}$, \\ Pascal Dubessay ${ }^{\mathrm{a}, \mathrm{b}}$, Andrea Fiorati ${ }^{\mathrm{c}}$, Nadia Pastori ${ }^{\mathrm{c}}$, Yves M. Galante $^{\mathrm{e}}$, \\ Philippe Michaud ${ }^{\mathrm{a}, \mathrm{b}}$ \\ a Université Clermont Auvergne, Université Blaise Pascal, Institut Pascal, BP 10448, F-63000, Clermont-Ferrand, France \\ ${ }^{\mathrm{b}}$ CNRS, UMR 6602, IP, F-63178, Aubière, France \\ c Department of Chemistry, Materials, and Chemical Engineering “G. Natta” and Local Unit INSTM, Politecnico di Milano, Piazza Leonardo da Vinci 32, \\ I-20133, Milano, Italy \\ d Università degli Studi e-Campus, Via Isimbardi 10, 22060, Novedrate, Como, Italy \\ e Istituto di Chimica del Riconoscimento Molecolare, CNR, Via Mario Bianco 9, 20131, Milano, Italy
}

\section{A R T I C L E I N F O}

\section{Article history:}

Received 4 January 2017

Received in revised form 30 January 2017

Accepted 8 February 2017

Available online 13 February 2017

\section{Keywords:}

TEMPO

Selective C- 6 oxidation

TEMPO-enzyme systems

Polysaccharides

Laccase

Nanofibers

\begin{abstract}
A B S T R A C T
The oxidation of natural polysaccharides by TEMPO has become by now an "old chemical reaction" which led to numerous studies mainly conducted on cellulose. This regioselective oxidation of primary alcohol groups of neutral polysaccharides has generated a new class of polyuronides not identified before in nature, even if the discovery of enzymes promoting an analogous oxidation has been more recently reported. Around the same time, the scientific community discovered the surprising biological and techno-functional properties of these anionic macromolecules with a high potential of application in numerous industrial fields. The objective of this review is to establish the state of the art of TEMPO chemistry applied to polysaccharide oxidation, its history, the resulting products, their applications and the associated modifying enzymes.
\end{abstract}

(C) 2017 Elsevier Ltd. All rights reserved.

\section{Contents}

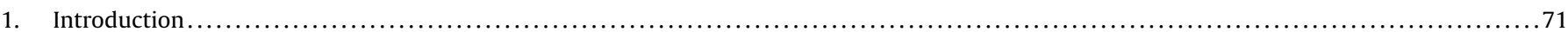

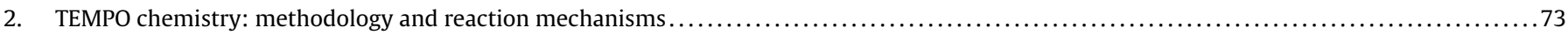

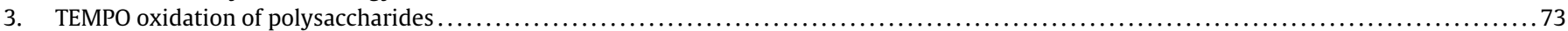

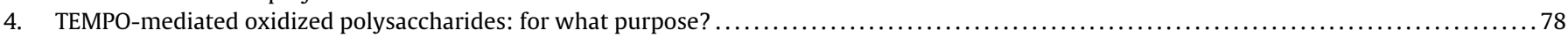

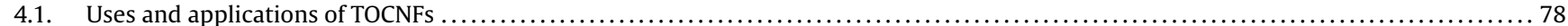

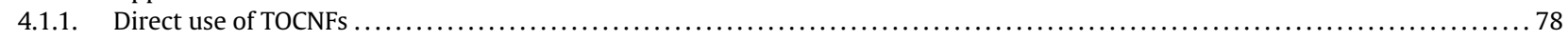

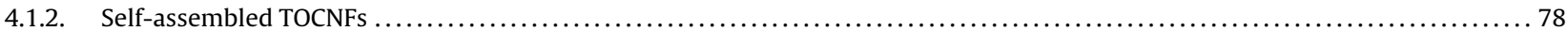

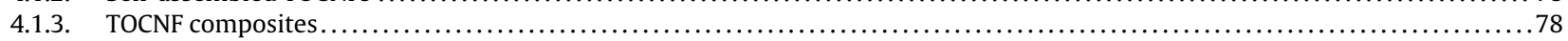

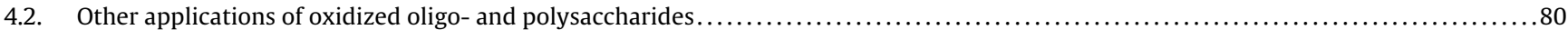

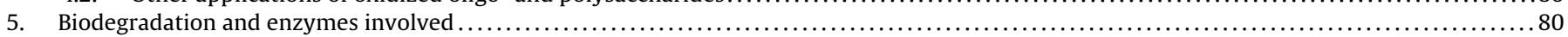

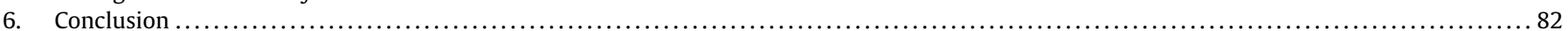

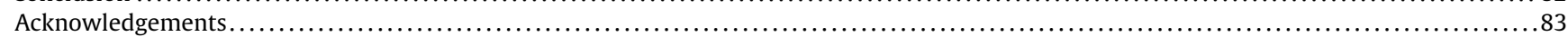

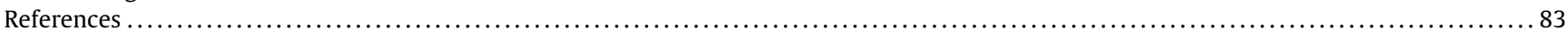

* Corresponding author at: Université Clermont Auvergne, Université Blaise Pascal, Institut Pascal, BP 10448, F-63000, Clermont-Ferrand, France.

E-mail address: guillaume.pierre@uca.fr (G. Pierre).

\section{Introduction}

In 1984, Semmelhack et al. wrote "Recent studies have demonstrated the ability of 2,2,6,6-tetramethylpiperidinyl-1-oxy (TEMPO) to mediate alcohol and amine oxidation by electrolysis, apparently via the nitrosonium ion" (Semmelhack, Schmid, Cortes, \& Chou, 1984). Even if this article is not the first dealing 


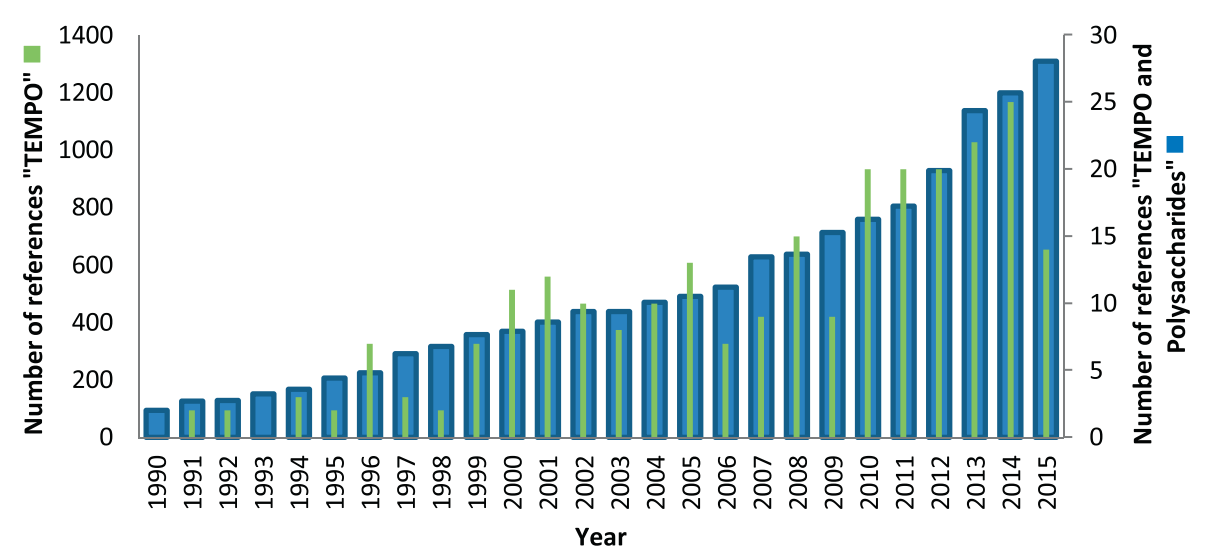

Fig. 1. Number of references per year between 1990 and 2015 using the key words "TEMPO" and the combination "TEMPO and Polysaccharides".

with oxidation of alcohols by TEMPO, Semmelhack et al. (1984) showed that selective oxidation of primary alcohol, in the presence of secondary ones, was feasible. The oxidation of primary alcohol groups of partially protected glycosides carbohydrates was then firstly published by Davis and Flitsch (1993). These authors used TEMPO/hypochlorite/bromide in a dichloromethane/water two-phase system. This publication is probably at the origin of polysaccharide oxidation by TEMPO, later reported by de Nooy, Besemer, and van Bekkum (1994) and de Nooy, Besemer, and van Bekkum (1958a). de Nooy et al. (1994) showed that only the hydroxymethyl groups of starch were oxidized, whereas the secondary hydroxyls remained unconverted. Their studies opened the way to a large number of publications and a research on science finder scholar in 2016 using "TEMPO" and the combination "TEMPO and Polysaccharide" found, respectively, 16251 and 277 (including 42 patents) references. Their evolution between 1990 and 2015 is given in Fig. 1.

TEMPO is a secondary amine nitrogen oxide (i.e., a nitroxyl radical) in which an unpaired electron is delocalized between the $N$ and $O$ atoms. This cyclic nitroxyl radical is only one species in a redox series of compounds (hydroxylamine, nitrosonium ion, TEMPO) generated by electron transfer. Briefly, during the oxidation of polysaccharides the nitrosonium ion derived from TEMPO is reduced into hydroxylamine under weakly alkaline conditions. The nitrosonium ion reacts with the hydroxylamine to regenerate TEMPO and is itself continuously regenerated in the reaction mixture by a primary oxidant, which is generally sodium hypochlorite. According to this mechanism, primary alcohol oxidation occurs with a high degree of selectivity (Bragd, van Bekkum, \& Besemer, 2004).

The interest of the scientific community and of some companies for new polyuronides is motivated by their valuable properties (which range from antiflocculation to adhesion, gelation, thickening, complexation, as well as a high number of biological activities). However, natural polyuronides are often complex heteropolymers frequently including neutral sugars and/or non-carbohydrate groups in their structures as is the case for alginates, pectic compounds, glycosaminoglycans, and some polyglucuronic acids (Elboutachfaiti, Delattre, Petit, \& Michaud, 2011; Lee \& Mooney, 2012; Pridz, 2015; Sundar Raj, Rubila, Jayabalan, \& Ranganathan, 2012). Before the development of TEMPO chemistry applied to polysaccharides, the oxidation of neutral polysaccharides, such as cellulose or starch, was performed by chemical processes with low efficiency and specificity, based on pioneering methods using nitrogen dioxide $\left(\mathrm{N}_{2} \mathrm{O}_{4}\right)$ or nitrite/nitrate in concentrated phosphoric acid (Maurer \& Reiff, 1943; Painter, 1977; Painter, Cesaro, Delben, \& Paoletti, 1985; Yackel \& Kenyon, 1942). Nitrogen dioxide does not exist as a sole molecule but is in equilibrium with nitrite $\left(\mathrm{N}_{2} \mathrm{O}_{4} \leftrightarrow \mathrm{NO}_{2}\right)$. Oxidation of polysaccharides with nitrogen dioxide leads to the depolymerization of biopolymers as a side reaction. The use of polysaccharides dissolved in phosphoric acid and oxidized by nitrites/nitrates has limited this depolymerization (Painter, 1977; Painter et al., 1985). Moreover, recent developments of cellulose oxidation with nitrogen dioxide as oxidant in high-pressure $\mathrm{CO}_{2}$ have also improved and simplified the post-oxidative salt-eliminating procedure after polysaccharide oxidation, even if the technique is not yet entirely satisfactory (Camy, Montanari, Rattaz, Vignon, \& Condoret, 2009). It should be noticed that other methods for oxidation of monosaccharides using strong oxidants such as hypochlorite, periodate or nitric acid lead to full oxidation of all hydroxyls groups, including primary and secondary OH's (Bragd et al., 2004). Milder reaction conditions with $\mathrm{Pt} / \mathrm{C}$, successfully applied to monosaccharides, have been disappointing when applied to polysaccharides (low oxidation yields) (Aspinall \& Nicolson, 1960). In this context, the first oxidations of polysaccharides with TEMPO were very attractive, considering their high selectivity, short times, milder and well controlled reaction conditions. This method was firstly applied to soluble or partially soluble polysaccharides like amylodextrin, alternan, pullulan, inulin, starch, xanthan or galactomannan (Chang \& Robyt, 1996; Delattre et al., 2015; de Nooy et al., 1994, 1995a; De Nooy, Besemer, van Bekkum, van Dijk, \& Smit, 1996; Pereira, Mahoney, \& Edgar, 2014; Sierakowski, Milas, Desbrières, \& Rinaudo, 2000; Tamura, Hirota, Saito, \& Isogai, 2010) before being extended to water-insoluble biopolymers, such as chitin, chitosan, curdlan, amylose and cellulose in which the high crystallinity reduces the access of the oxidant to the hydroxyl functions (Delattre et al., 2009; Isogai \& Kato, 1998; Meng, Fu, \& Lucia, 2016; Muzzarelli et al., 2000; Pierre et al., 2013; Tamura, Wada, \& Isogai, 2009). This reaction yielded soluble polysaccharides, like for substitution reactions of hydroxyl groups by carboxymethyl ether or sulfate ester groups. The new polyuronides obtained and notably oxidized cellulose have been successfully tested for their biological, rheological and physico-chemical properties (Delattre et al., 2009; Elboutachfaiti, Petit et al., 2011; Stilwell et al., 1997; Zhang et al., 2010) in academic laboratories, often within collaborations with a few companies (Delattre et al., 2009). However, and to the best of our knowledge, no polyuronides derived from TEMPO oxidation had a real commercial development with large scale production, even if oxidized cellulose was claimed to be a raw material for medical devices, e.g. absorbable hemostats, adhesion barriers, sutures, and tissue engineering. Indeed, issues of polysaccharide depolymerization were claimed. A competition between polyelectrolyte swelling and chain scission often takes place during the first hours of the oxidation reaction (Coseri, Bercea, Harabagiu, \& Budtova, 2016). Alternative approaches, such as the use of laccases with TEMPO, instead of the 
traditional TEMPO and $\mathrm{NaBr} / \mathrm{NaOCl}$ chemistry were successfully tested, but not really further developed (Mathew \& Adlercreutz, 2009). Some of the polysaccharidic structures obtained are very original and not described in literature prior to the introduction of TEMPO chemistry. Among them, $\beta$-(1,4)-polyglucuronic acid (also called glucuronan) have been investigated for their biodegradability and a new family of polysaccharide lyases called glucuronan lyases (EC 4.2.2.14) has been identified (Delattre, Michaud, Keller, et al., 2006; Konno, Igarashi, Habu, Samejima, \& Isogai, 2009). This surprising result could suggest the existence of a putative source of this polyglucuronic acid in nature, which could explain the conservation of these enzymes in fungal genomes. The present review provides insights into TEMPO chemistry applied to oxidation of polysaccharides, their physico-chemical and biological properties, as well as their biodegradability.

\section{TEMPO chemistry: methodology and reaction mechanisms}

In chemical organic synthesis, the stable tetraalkylnitroxyl radical TEMPO was well described as an efficient oxidation catalyst of choice, mainly used for the industrial oxidation of organometallic, sulfide and, in particular, of alcohols to generate carbonyl compounds (Ciriminna \& Pagliaro, 2010; Vogler \& Studer, 2008). Historically, one of the first descriptions of alcoholic compound oxidation using TEMPO derivatives was reported by Golubev, Rozantsev, and Neiman (1966). In their study, these authors have shown the possibility to produce high yields of acetaldehyde by treatment of ethanol with oxoammonium chloride salt (Fig. 2A). Afterward, Cella, Kelley and Kenehan (1975) developed a chemical synthesis strategy to generate carboxylic acid compounds via oxidation of alcohols by a reaction with meta-chloroperbenzoic acid (mCPBA) in the presence of 2,2,6,6tetramethylpiperidine used as catalyst (Fig. 2B). As reported by the authors, mCPBA first oxidized the 2,2,6,6-tetramethylpiperidine to produce the stable radical TEMPO, which was directly oxidized to an oxoammonium cation derivative. The latter was considered as the primary oxidant for the conversion of alcohol to carboxylic acid. In later years, Anelli, Banfi, Montanari and Quici (1987) described the oxidation of primary alcohols in the presence of 4-methoxy-2,2,6,6-tetramethylpiperidine-1-oxyl (4-MeO-TEMPO) as catalyst to efficiently generate aldehydes or carboxylic acids by using a water/dichloromethane biphasic system under alkaline conditions in the presence of potassium bromide, sodium hypochlorite and sodium bicarbonate (Fig. 2C). A few years later, Anelli, Banfi, Montanari and Quici (1989) have proposed another strategy for the oxidation of diols using oxammonium salts as reagent. Indeed, these authors were the first to report a specific oxidation of 1,5-pentanediol and 1,4-butanediol by using a system of TEMPO with sodium hypochlorite and sodium bromide in a water/dichloromethane biphasic system. These reactions were carried out in aqueous $\mathrm{NaOCl} /$ dichloromethane at $10-15^{\circ} \mathrm{C}$ under basic conditions ( $\mathrm{pH} 9.3$ ), in the presence of TEMPO ( $0.01 \mathrm{~mol} \mathrm{~L}^{-1}$ equiv) and potassium bromide $\left(0.10 \mathrm{~mol} \mathrm{~L}^{-1}\right.$ equiv). Thus far, the method using TEMPO catalyst has become one of the better described chemical approaches to easily convert primary and secondary alcohol groups to ketones, aldehydes and carboxylic compounds (Fig. 2D) (Adam, Saha-Moller \& Ganeshpure, 2001; Bobbitt \& Flores, 1988; Caron, Dugger, Ruggeri, Ragan, \& Brown Ripin, 2006; Ciriminna \& Pagliaro, 2010; Elboutachfaiti, Delattre et al., 2011; Elboutachfaiti, Petit et al., 2011; Sheldon, 2007; Sheldon, 2013; Sheldon \& Arenas, 2004; Vogler \& Studer, 2008). Initially described as a highly selective oxidation of primary alcohol groups, in particular for monosaccharides (de Nooy et al., 1994), De Nooy et al. (1996) pointed out some issues on pullulan with some oxidations of secondary alcohols to ketones. More recently, Su et al. (2013) suspected the oxidation of other hydroxyl groups than the one in C6 position in agarose units. In the same way, secondary reactions were also observed on carrageenan, caused by a specific overoxidation of 3,6-anhydrogalactose (Cosenza, Navarro, Pujol, Damonte, \& Stortz, 2015). As commonly proposed in the literature (Adam et al., 2001; Bobbitt \& Flores, 1988; Cella et al., 1975; Elboutachfaiti, Delattre et al., 2011; Elboutachfaiti, Petit et al., 2011; Sheldon, 2013), alcohol oxidation reaction by using oxoammonium salt is performed with a catalytic mechanism which allows the in situ generation of oxoammonium derivatives by one-electron oxidation of nitroxide compounds, such as TEMPO, either by using an electrochemical process or by adding an oxidant such as mCPBA or hypochlorite derivatives. Oxidation can be carried out in: (i) biphasic media systems, (ii) an organic solvent and, (iii) aqueous media (Ciriminna \& Pagliaro, 2010; Sheldon, 2007; Vogler \& Studer, 2008). It was clearly confirmed that the oxoammonium ion generated by oxidation of TEMPO with an oxidant such as sodium hypochlorite at low temperatures $\left(0-4{ }^{\circ} \mathrm{C}\right)$ and under basic conditions ( $\mathrm{pH}$ 9-12) could regioselectively oxidize several alcohols and polyalcohols (Bailey, Bobbitt, \& Wiberg, 2007; Ciriminna \& Pagliaro, 2010). Some authors have investigated the effect of $\mathrm{pH}$ onto the chemoselective oxidation of alcohol using oxoammonium derivatives, such as TEMPO. As observed by Bailey et al. (2007), under alkaline condition, secondary alcohols are much more slowly oxidized than primary ones, while under acidic and/or neutral conditions, the opposite phenomenon occurs. Semmelhack, Schmid, and Cortes (1986) and Bailey et al. (2007) proposed that under alkaline conditions the oxidation of alcoholic compounds using TEMPO is initiated by the specific formation of a reactive complex as presented in Fig. $2 \mathrm{E}$. This reactive complex could be formed by nucleophilic attack of the alcoholate anion $\left(\mathrm{RO}^{-}\right)$on: (i) oxygen atom or (ii) nitrogen atom from the newly generated 2,2,6,6-tetramethylpiperidine-1-oxoammonium cation. Finally, an intramolecular proton transfer gives an intermediate complex leading to the formation of carbonyl compound (from alcohol oxidation) and hydroxylamine derivative (from TEMPO).

As well-established by Adam et al. (2001), the use of nonmetal oxidation catalysts, such as TEMPO and its derivatives, have gained increasing interest for several reasons: (i) several of such catalysts derivatives are commercially available at low cost, (ii) these catalysts are user-friendly under aqueous system reaction conditions, (iii) these catalysts can react with all common oxidizing agents, such as peracids, sodium hypochlorite, mCPBA acid or monoperoxysulfate to produce oxoammonium salt and finally, (iv) these catalysts are very resistant to auto-oxidation. Consequently, TEMPO radical and all its derivatives are generally used as highly regio-selective oxidation reagents in industrial field for the specific synthesis of chemical, cosmetics, pharmaceuticals, fragrances, flavors, etc. (Ciriminna \& Pagliaro, 2010; Elboutachfaiti, Delattre et al., 2011; Elboutachfaiti, Petit et al., 2011). Ciriminna \& Pagliaro published a very interesting review about why and how processes using TEMPO-mediated oxidation have become one of the main tools in industrial organic syntheses. As a consequence, it is important to mention that in TEMPO chemistry, the regioselective oxidation of polysaccharides was described since the nineties for the generation of new techno-functional and bioactive anionic polysaccharides.

\section{TEMPO oxidation of polysaccharides}

For the last two decades, TEMPO has been in use in sugar chemistry. Much attention has been given to the selective oxidation of hydroxyl groups of carbohydrate to generate carboxyl and/or aldehyde groups. Yet, few papers deal with fundamental and chemical understanding for using TEMPO on polysaccharides and even fewer 
(A)

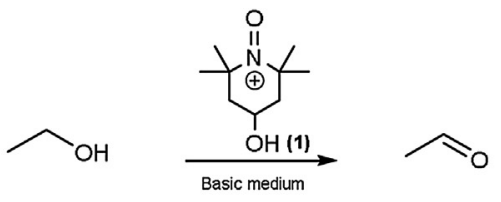

(B)

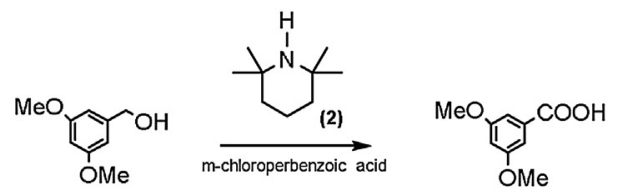

(C)

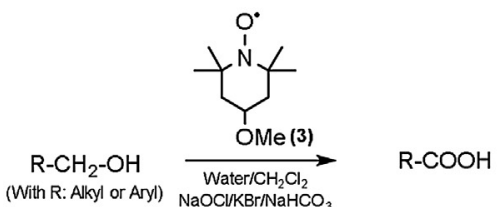

(E)

STEP 1:

(a)

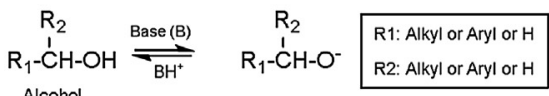

(b)

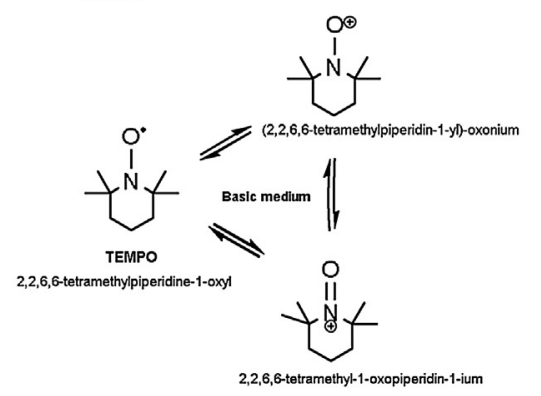

(D)

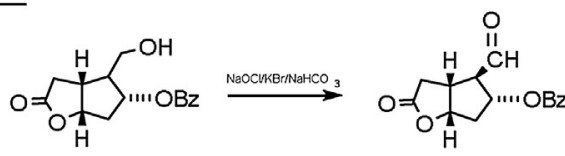
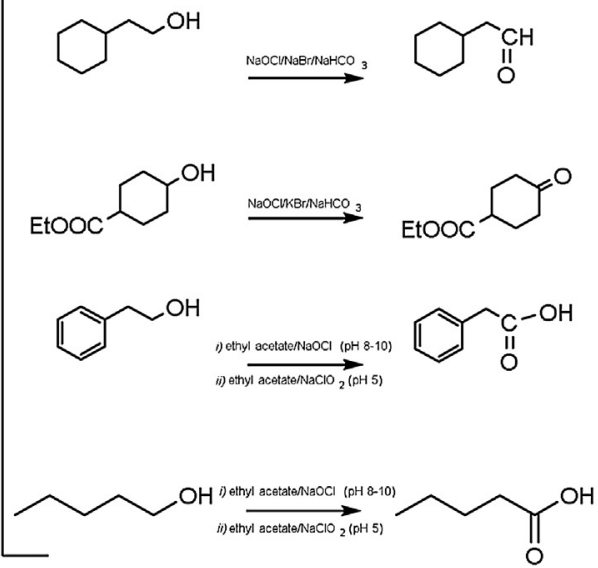

STEP 2:

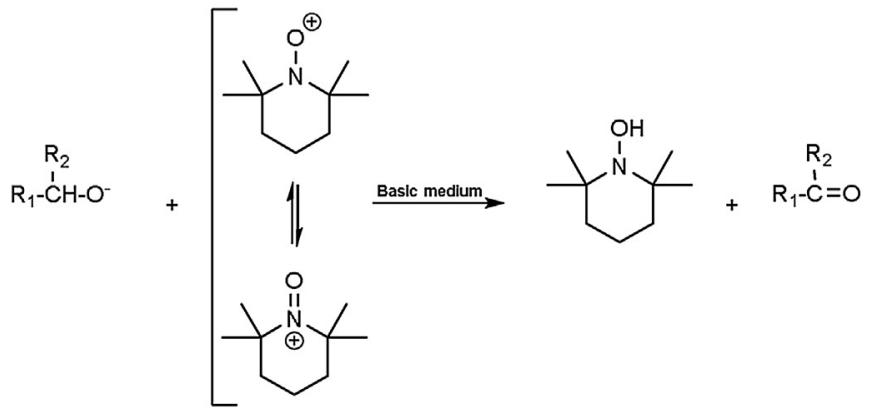

Fig. 2. Examples of alcoholic compounds oxidation strategies using TEMPO and derivatives. (A) Oxidation of ethanol onto acetaldehyde using 4-hydroxy-2,2,6,6tetramethyl-1-oxopiperidin-1-ium (1) (adapted from Golubev et al., 1966); (B) oxidation of (3,5-dimethoxyphenyl)-methanol onto 3,5-dimethoxybenzoic acid using 2,2,6,6-tetramethylpiperidine (2) and $m$-chloroperbenzoic acid (adapted from Cella et al., 1975); (C) general oxidation of alcohol onto carboxylic acid using Water/ $\mathrm{CH}_{2} \mathrm{Cl}_{2}$ biphasic system and 4-methoxy-TEMPO/NaOCl$/ \mathrm{KBr} / \mathrm{NaHCO}_{3}$ (3) (adapted from Anelli et al., 1987); (D) examples of syntheses of ketones, aldehydes and carboxylic acid compounds by using TEMPO (adapted from Caron et al., 2006; Ciriminna \& Pagliaro, 2010) and, (E) Alcohol oxidation mechanism under alkaline media using TEMPO (adapted from Bailey et al., 2007; Semmelhack, Schmid, \& Cortes, 1986).

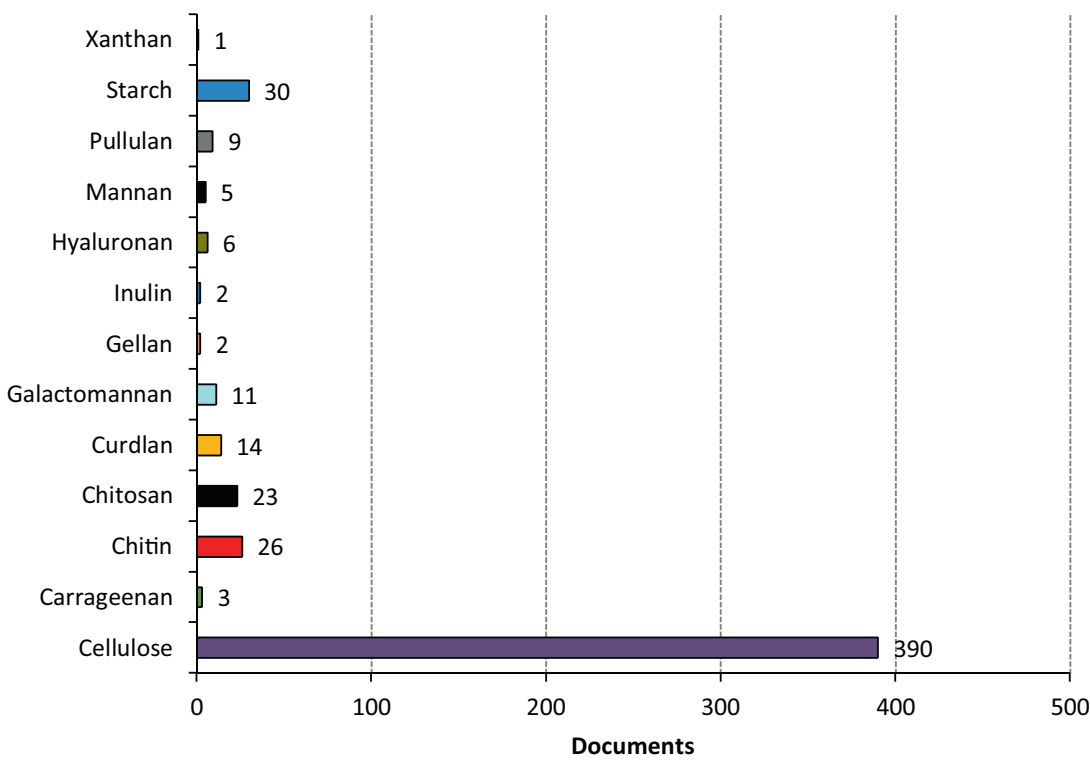

Fig. 3. Document search results since 2000 on Scopus website using specific keywords association "TEMPO" and "oxidation" and a variable one. 
address recent advances (oxidation performance, etc.) on its use. Current studies are aimed at creating, modulating or improving the physico-chemical and/or biological properties of various native polysaccharides (Fig. 3).

TEMPO oxidation process were demonstrated to offer clear advantages comparing to enzymatic or metal-catalyzed oxidation (Bragd et al., 2004) such as (i) high reaction rate, (ii) high conversion ratio, (iii) high selectivity, (iv) partial decrease of molecular weight of polysaccharides during the process (if controlled), ( $v$ ) low cost as co-oxidant.

A broad range of polyuronic analogues can be formed from their corresponding native polysaccharides via a reactive aldehydeintermediate which is present at low concentration throughout the oxidation reaction (de Nooy, Besemer, \& van Bekkum, 1995b). As previously explained (see part 2.), the nitrosonium salt, as the active oxidizing species, must be regenerated in situ. Different systems of suitable primary oxidants have been described in the literature and sodium hypochlorite showed very good results (Fig. 4), especially in the presence of catalytic amounts of sodium bromide (Bragd, Besemer, \& van Bekkum, 2002; Bragd et al., 2004). Additives such as $\mathrm{KBr}$ or $\mathrm{NaBr}$ are used to boost the rate of oxidation reaction (Tavernier, Delattre, Petit, \& Michaud, 2008).

Alternative oxidation systems have also been reported in the review of Bragd et al. (2004) such as manganese dioxide, copper salt with bipyridine complex, silver catalysts with sodium peroxodisulfate and peracetic acid (Bragd et al., 2002). Overall, TEMPO assisted oxidation in aqueous systems of cold water-soluble polysaccharides (such as xanthan, pullulan, galactomannan) compared to cold-water-insoluble systems (such as chitin, chitosan, amylopectin) gave better results in terms of oxidation degree or final molecular weight (Bragd et al., 2004). Table 1 gives a large overview of recent TEMPO-mediated oxidation of carbohydrates using different oxidant systems and their polyuronic analogues.

Cellulose and cellulose (nano)fibers are probably the most studied polysaccharides for TEMPO oxidation, especially by the well-known Isogai's team from Japan (Isogai, Saito, \& Isogai, 2010). In many papers, unavoidable depolymerizations of CelloUronic Acids (CUA) by a $\beta$-elimination mechanism have been observed in a $\mathrm{pH}$ range from 9 to 12 . Delattre, Michaud, Elboutachfaiti, Courtois, \& Courtois (2006a) obtained oligo-CUA from TEMPO oxidation of cellulose and purified their products by size-exclusion chromatography. Some authors proposed alternative routes to reduce $\beta$-elimination by using 4 -acetamido-TEMPO/ $\mathrm{NaClO} / \mathrm{NaClO}_{2}$ system at pH 4-7 (Hiraoki, Fukuzumi, Ono, Saito, \& Isogai, 2014; Hirota, Tamura, Saito, \& Isogai, 2009) or TEMPO electromediated oxidation (Isogai et al., 2010). In the latter paper, the authors were able to keep the original fibrous and morphology of CUA fibers. These same authors extended the same procedure to curdlan and amylodextrins, obtaining impressive degrees of oxidation, higher than $90 \%$. Today, cracking wood is still a challenge especially for the valorization of byproducts/wastes from papermaking and wood industries. Preparing TEMPO-Oxidized Cellulose NanoFibers (TOCNFs) for the creation of new bio-based applications is one possible solution to address this challenge. Wood cellulose material can be easily converted to individual micro- and nanofibers of different lengths, sizes and diameters. These characteristics are involved in TEMPO chemistry and can lead to various TOCNFs (Isogai, Saito, \& Fukuzumi, 2011). Recently, Meng et al. (2016) also highlighted the role of heteropolysaccharides in developing TOCNFs by using four fibers resources, i.e. bleached Kraft pulps of softwood, pine and eucalyptus hardwood and non-woods varieties such as bamboo and bagasse. Due to the presence of xylans which limit the chemical accessibility of cellulose, the formation of carboxylate groups was reduced. Galactoglucomannans were also involved in the consumption of $\mathrm{NaClO}$, limiting the oxidation of TOCNFs.
Regiospecifically carboxylated chitins have been of primary interest as they mimic glycosaminoglycan (GAG) structures and can present interesting properties such as neuroprotection, wound healing or for cosmetic applications (DeAngelis, 2012).6-oxychitins and 6-oxychitosans have thus been investigated in many papers, in terms of TEMPO oxidation reactions as well as for their biological properties. Muzzarelli, Muzzarelli, Cosani, and Terbojevich (1999) produced anionic derivatives fully soluble in a wide $\mathrm{pH}$ range from lobster, crab and fungal chitins with very good yields. In the same way, Huang et al. (2013) prepared 6-carboxy- $\beta$-chitin derivatives from squid pens with oxidation degrees up to $75 \%$. Increasing $\mathrm{NaOCl}$ amounts ( $\mathrm{mmol} / \mathrm{g}$ chitin) allowed them to enhance the conversion on C6 position into carboxylates. Pierre et al. (2013) performed one-pot oxidation of chitosan with TEMPO-NaOCl-NaBr system and obtained yields close to $14 \%(\mathrm{w} / \mathrm{w})$, consistent with previous reports in the literature for chitosan and $\beta$-chitin. The carboxylate content of their derivatives was $40 \%$. These authors also highlighted a strong depolymerization phenomenon of the molecular weight of chitosan, from DP (Degree of Polymerization) 593-12 and 7 for their derivatives. Bordenave, Grelier, and Coma (2008) also described low products yields and drastic decreases of the polymer molecular weight. Yoo et al. (2005) sequentially oxidized chitosan samples from 25 to $100 \%$ under specific TEMPO conditions. In this paper, a drop in solubility of 6-oxychitosans was observed for the highest degrees of oxidation, due to aggregation among the derivatives by charge-charge interactions. Hyaluronan, scleroglucan, mannan and galactomannan have also been used for TEMPO-oxidation to provide novel GAG polymers (Elboutachfaiti, Delattre et al., 2011; Elboutachfaiti, Petit et al., 2011). Ďurana, Lacík, Paulovičová, and Bystrický (2006) have thus functionalized mannans from four pathogenic yeasts, i.e. Candida albican, Candida tropicalis, Candida glabrata and Candida parapsilosis, using various oxidation systems including TEMPO-NaOCl-NaBr and studied their immunological properties. In 2000, Sierakowski et al. successfully described TEMPO oxidation of galactomannans extracted from the seeds of Leucaema leucocephala. Sakakibara, Sierakowski, Lucyszyn, and de Freitas (2016) highlighted the role of chain flexibility during the TEMPO-mediated oxidation of guar and locust bean galactomannans. Mannose (Man) units were preferentially oxidized because of the reduced availability of HO-6 groups on Galactose (Gal) side chains. Indeed, the authors observed hydrogen bonding involving the Man HO-3 group and the HO-6 and HO-2 groups of the vicinal Gal unit, but also the increase in the galactosyl side chain induced a lowering in the chain extension, as already described by Petkowicz, Reicher, and Mazeau (1998). $\beta$-Elimination process was also better onto locust bean galactomannan which is less ramified than guar galactomannan. In the last fifteen years, others authors have investigated oxidation of galactomannans, mostly to create new bio-based materials. The interesting part here is probably the use of TEMPO system assisted by laccase to generate oxidized derivatives (Lavazza et al., 2011; Merlini, Boccia, Mendichi, \& Galante, 2015; Rossi et al., 2016). Most of the classical primary oxidants used for TEMPO oxidation produce large amounts of salts. Greener chemical reactions should been looked for improving life cycle assessment (LCA) of the generated oxidized derivatives. Indeed, the use of strong secondary oxidants limits the application of TEMPO on carbohydrates. Many studies are aimed at finding environmentally friendly methods, especially for regenerating the oxidant. For example, Lemoine et al. (2000) studied sono-catalysed $(500 \mathrm{kHz})$ TEMPO-mediated oxidation of sucrose without the addition of sodium bromide. Isogai et al. (2010) also developed a TEMPO electro-mediated oxidation of curdlan, amylodextrin and regenerated cellulose. Overall, attention should be paid to electrochemical, but also to immobilized-TEMPO oxidations as reviewed by Bragd et al. (2004). Enzyme-based TEMPO systems exploiting oxidative enzymes are another suitable 
Table 1

Some TEMPO-mediated oxidations of various polysaccharides since the 2000s.

\begin{tabular}{|c|c|c|c|c|c|c|c|c|}
\hline \multirow[t]{2}{*}{ Substrate } & \multirow[t]{2}{*}{ TEMPO System } & \multirow[t]{2}{*}{ Yield (\%) } & \multirow[t]{2}{*}{$\mathrm{pH}$} & \multirow[t]{2}{*}{$\mathrm{T}\left({ }^{\circ} \mathrm{C}\right)$} & \multirow{2}{*}{$\begin{array}{l}\text { Oxidation } \\
\text { ratio }(\%)\end{array}$} & \multicolumn{3}{|c|}{ Molecular weight (kDa)References } \\
\hline & & & & & & Initial & Final & \\
\hline Agarose & $\mathrm{NaOCl} / \mathrm{NaBr}$ & - & 10.5 & $\mathrm{rt}^{\mathrm{c}}$ & 30 & - & 4 & Su et al. (2013) \\
\hline Carrageenan & $\mathrm{NaOCl} / \mathrm{NaBr}$ & $80-90$ & $9.4-10.5$ & 0 & - & $\begin{array}{l}215 \\
460\end{array}$ & $\begin{array}{l}93-65 \\
167-16\end{array}$ & Cosenza et al. (2015) \\
\hline \multirow[t]{9}{*}{ Cellulose } & $\begin{array}{l}\mathrm{NaOCl} / \mathrm{NaBr} \\
\mathrm{NaOCl} / \mathrm{NaBr}\end{array}$ & $\begin{array}{l}78-91 \\
98\end{array}$ & $\begin{array}{l}10.5 \\
10.5\end{array}$ & $\begin{array}{l}\mathrm{rt} \\
\mathrm{rt}\end{array}$ & $\begin{array}{l}54-76 \\
>23\end{array}$ & $\begin{array}{l}>80 \\
137\end{array}$ & $\begin{array}{l}<37 \\
78.1\end{array}$ & $\begin{array}{l}\text { Saito and Isogai (2004) } \\
\text { Saito, Yanagisawa, and Isogai } \\
\text { (2005) }\end{array}$ \\
\hline & $\mathrm{NaOCl} / \mathrm{NaBr}$ & $41-51$ & 10.5 & 4 & 65 & - & - & $\begin{array}{l}\text { Delattre, Michaud, } \\
\text { Elboutachfaiti et al. (2006) }\end{array}$ \\
\hline & 4-acetamide-TEMPO/NaClO $/ \mathrm{NaClO}_{2}$ & $41-71$ & $3.5-6.8$ & $40-60$ & $73-84$ & 122 & $>40$ & Hirota et al. (2009) \\
\hline & $\begin{array}{l}\mathrm{EM}^{\mathrm{a}} \\
\text { 4-acetamide-TEMPO/NaClO} / \mathrm{NaClO}_{2}\end{array}$ & $91-98$ & 6.8 & $\mathrm{rt}$ & $>60$ & 54 & $>18$ & Isogai et al. (2010) \\
\hline & $\mathrm{NaOCl} / \mathrm{NaBr}$ & - & 10 & $\mathrm{rt}$ & - & 11.7 & 11 & Hiraoki et al. (2014) \\
\hline & 4-acetamide-TEMPO/NaClO/ $\mathrm{NaClO}_{2}$ & - & 6.3 & 40 & - & 11.7 & $\mathrm{na}^{\mathrm{d}}$ & Hiraoki et al. (2014) \\
\hline & LMS $^{\mathrm{b}} /$ TEMPO or 4 -amino TEMPO & - & 7 & 30 & - & - & 46.8 & Jaušovec et al. (2015) \\
\hline & $\mathrm{NaOCl} / \mathrm{NaBr}$ & - & 10 & 25 & $>80$ & - & - & Meng et al. (2016) \\
\hline & Sono-assisted TEMPO $\mathrm{NaOCl} / \mathrm{NaBr}$ & $67-99$ & 10 & 30 & $>60$ & - & - & Rohaizu and Wanrosli (2017) \\
\hline \multirow[t]{6}{*}{ Chitin/chitosan } & $\mathrm{NaOCl} / \mathrm{NaBr}$ & $>90$ & 10.8 & $\mathrm{rt}$ & - & - & $<10$ & Muzzarelli et al. (1999) \\
\hline & $\mathrm{NaOCl} / \mathrm{NaBr}$ & $50-95$ & 10.75 & $<5$ & - & - & $3200-26$ & Kato et al. (2004) \\
\hline & $\mathrm{NaOCl} / \mathrm{NaBr}$ & - & 10.8 & 30 & $25-100$ & - & - & Yoo et al. (2005) \\
\hline & $\mathrm{NaOCl} / \mathrm{NaBr}$ & 2 & 10.8 & $5 / \mathrm{rt}$ & - & $400-165$ & - & Bordenave et al. (2008) \\
\hline & $\mathrm{NaOCl} / \mathrm{NaBr}$ & $34-74$ & 10.8 & $\mathrm{rt}$ & $>40$ & - & $2.1-1.2$ & Huang et al. (2013) \\
\hline & $\mathrm{NaOCl} / \mathrm{NaBr}$ & 13.7 & 10.75 & 5 & 40 & 98 & - & Pierre et al. (2013) \\
\hline \multicolumn{9}{|l|}{ Crude material } \\
\hline Cashew gum & $\mathrm{NaOCl} / \mathrm{NaBr}$ & 96 & 9.3 & 5 & 68 & - & - & $\begin{array}{l}\text { Cunha, Maciel, Sierakowski, de } \\
\text { Paula, and Feitosa (2007) }\end{array}$ \\
\hline Wood cellulose & $\mathrm{NaOCl} / \mathrm{NaBr} / \mathrm{NaClO}{ }_{2}$ & - & 4.8 & $\mathrm{rt}$ & - & 502 & 374 & Hiraoki et al. (2014) \\
\hline \multirow[t]{3}{*}{ Curdlan } & $\mathrm{NaOCl} / \mathrm{NaBr}$ & 80 & 11 & 4 & $25-100$ & 560 & 500 & Delattre et al. (2009) \\
\hline & $\begin{array}{l}\text { EM } \\
\text { 4-acetamide-TEMPO } / \mathrm{NaClO} / \mathrm{NaClO}_{2}\end{array}$ & $91-92$ & 6.8 & $\mathrm{rt}$ & $>90$ & 1100 & 268 & Isogai et al. (2010) \\
\hline & 4 -acetamide-TEMPO/NaClO $/ \mathrm{NaClO}_{2}$ & 90 & 4.7 & 35 & 95 & 1100 & 197 & Tamura et al. (2010) \\
\hline \multirow[t]{5}{*}{ Galactomannan } & $\mathrm{NaOCl} / \mathrm{NaBr}$ & $>92$ & 9.3 & 3 & $38-66$ & 1330 & 800 & Sierakowski et al. (2000) \\
\hline & LMS & - & $4-7.5$ & $30-70$ & - & - & - & Lavazza et al. (2011) \\
\hline & LMS and/or $\mathrm{NaOCl} / \mathrm{NaBr}$ & - & $7 / 9.3$ & $35 / 0$ & - & $2425-1016$ & - & Merlini et al. (2015) \\
\hline & LMS & - & 7 & 35 & - & - & - & Rossi et al. (2016) \\
\hline & $\mathrm{NaOCl} / \mathrm{NaBr}$ & - & 9.3 & 5 & $0-100$ & $270-240$ & $200-46$ & Sakakibara et al. (2016) \\
\hline \multirow[t]{2}{*}{ Gellan } & $\mathrm{NaOCl} / \mathrm{NaBr}$ & $>89$ & 10 & $\mathrm{rt}$ & $22.5-100$ & 512 & 19.4 & Elboutachfaiti et al. (2010) \\
\hline & $\mathrm{NaOCl} / \mathrm{NaBr}$ & 89-95 & 10 & 4 & $22.5-100$ & - & - & $\begin{array}{l}\text { Elboutachfaiti, Delattre et al. } \\
\text { (2011) and Elboutachfaiti, Petit } \\
\text { et al. (2011) }\end{array}$ \\
\hline \multirow[t]{2}{*}{ Glucomannan } & $\mathrm{NaOCl} / \mathrm{NaBr}$ & - & 10 & $\mathrm{rt}$ & $15-80$ & - & - & Chen et al. (2014) \\
\hline & $\mathrm{NaOCl} / \mathrm{NaBr}$ & - & 10 & $\mathrm{rt}$ & $30-80$ & $2000-500$ & $153-131$ & Chen et al. (2016) \\
\hline \multirow[t]{2}{*}{ Inulin } & 4-AcNH-TEMPO/oxone/NaBr & - & 8.2 & $<5$ & 60 & na & na & Bragd et al. (2002) \\
\hline & 4-AcNH-TEMPO/peracetate/NaBr & - & 8.2 & $<5$ & 80 & & & Bragd et al. (2002) \\
\hline Hyaluronan & $\mathrm{NaOCl} / \mathrm{NaBr}$ & - & 10.2 & 0 & $31-71$ & 1350 & $780-510$ & $\begin{array}{l}\text { Jiang, Drouet, Milas, and } \\
\text { Rinaudo (2000) }\end{array}$ \\
\hline Mannan & $\mathrm{NaOCl} / \mathrm{NaBr}$ & - & 10 & 2 & $24-28$ & $62.3-44.3$ & na & Ďurana et al. (2006) \\
\hline Polyuronan & $\mathrm{NaOCl} / \mathrm{NaBr}$ & $>60$ & 10.8 & $\mathrm{rt}$ & $20-75$ & - & - & Muzzarelli et al. (2000) \\
\hline \multirow[t]{4}{*}{ Pullulan } & 4-AcNH-TEMPO/oxone/NaBr & - & 8.2 & $<5$ & 85 & na & na & Bragd et al. (2002) \\
\hline & 4-acetamide-TEMPO/NaClO/ $\mathrm{NaClO}_{2}$ & 90 & 4.7 & 35 & 8 & - & - & Tamura et al. (2010) \\
\hline & $\mathrm{NaOCl} / \mathrm{NaBr}$ & 95 & 9.4 & 2 & - & 450 & - & Pereira et al. (2014) \\
\hline & $\mathrm{NaOCl} / \mathrm{NaBr}$ & - & 10 & - & $10-100$ & 220 & $182-28$ & Spatareanu et al. (2014) \\
\hline \multirow[t]{5}{*}{ Starch/Dextrin } & 4-AcNH-TEMPO/oxone/NaBr & - & $7.5-9$ & $5-15$ & $60-90$ & na & na & Bragd et al. (2002) \\
\hline & 4-AcNH-TEMPO/peracetate/ $\mathrm{NaBr}$ & - & 8.2 & $<5$ & 858 & na & na & Bragd et al. (2002) \\
\hline & EM & $91-92$ & 6.8 & $\mathrm{rt}$ & & 60 & 53.9 & Isogai et al. (2010) \\
\hline & 4-acetamide-TEMPO/NaClO $/ \mathrm{NaClO}_{2}$ & & & & & & & \\
\hline & 4-acetamide-TEMPO/NaClO/ $\mathrm{NaClO}_{2}$ & 83 & 4.7 & 35 & $>39.3$ & - & - & Tamura et al. (2010) \\
\hline Xanthan & $\mathrm{NaOCl} / \mathrm{NaBr}$ & $>90$ & 10 & 4 & 98 & 1910 & 585 & Delattre et al. (2015) \\
\hline
\end{tabular}

a EM: ElectroMediated.

b LMS: Laccase-Mediator System.

c rt: Room temperature.

${ }^{d}$ na: Not accurate. 


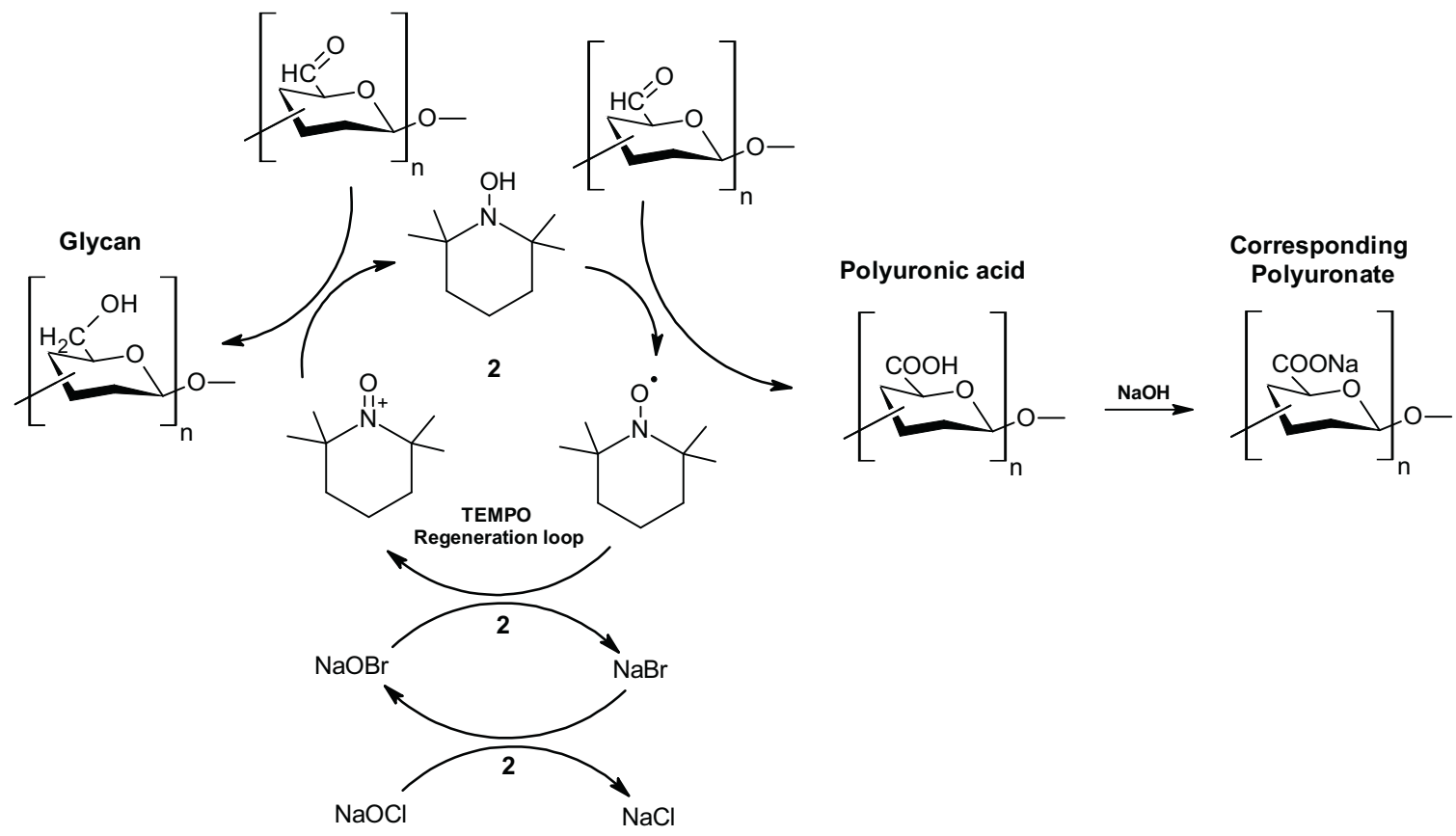

Fig. 4. TEMPO-mediated oxidation of glycans to generate their corresponding polyuronates with NaOCl/NaBr system, adapted from Elboutachfaiti, Delattre et al. (2011).
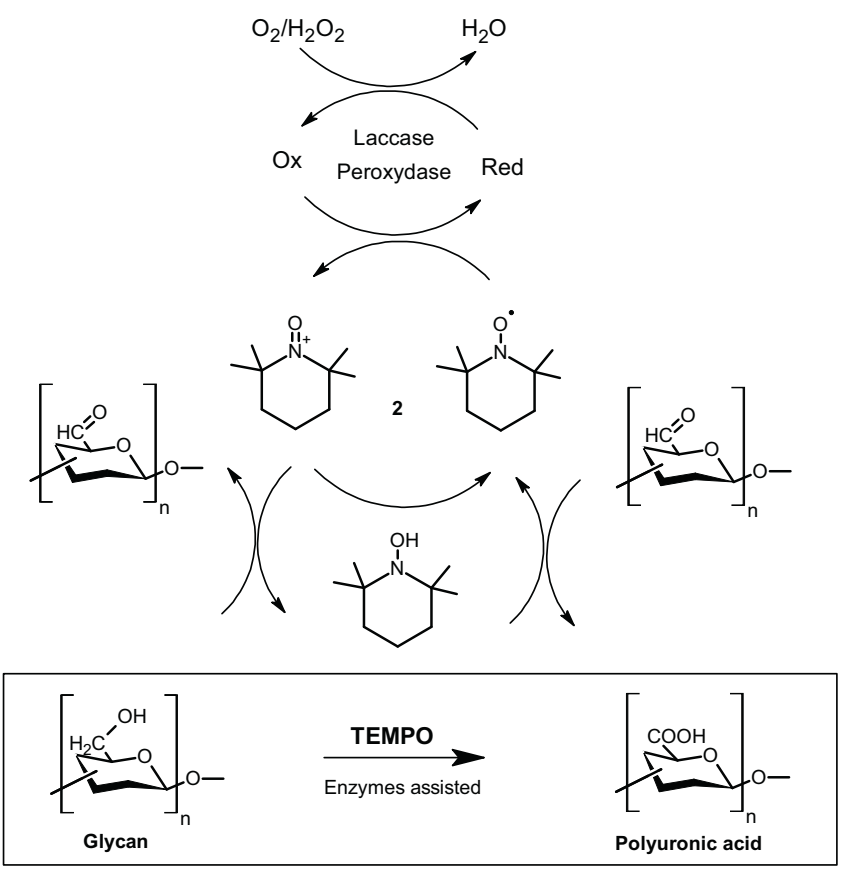

Fig. 5. Mechanisms of glycan oxidation by TEMPO/laccase $/ \mathrm{O}_{2}$ or TEMPO/peroxydase $/ \mathrm{H}_{2} \mathrm{O}_{2}$ systems, adapted from Bragd et al. (2004).

alternative to salt-based TEMPO-oxidative systems. Enzymesassisted TEMPO oxidation allows the regeneration in situ of nitrosonium salt where only oxygen (in the case of laccase) or hydrogen peroxide (with peroxydase) is the final electron acceptor in the course of the reaction (Fig. 5).

Laccase (EC 1.10.3.2.), which belongs to the oxyreductase family, could be a good candidate to optimize green chemical synthesis of oxidized compounds with only water as by-product (Marzorati, Danieli, Haltrich, \& Riva, 2005). The efficiency of the system TEMPO/laccase from Trametes pubescens $/ \mathrm{O}_{2}$ was tested with mono- and disaccharides but also cellulose derivatives. Mathew \& Adlercreutz (2009) performed similar experiments by using TEMPO combined with laccase to oxidize granular potato starch under mild and environmentally friendly conditions. Other enzymes-assisted oxidations have been reported on polysaccharides such as (i) starch and cellulose suspensions (Viikari, Buchert, \& Kruus, 1999a; Viikari et al., 1999b), (ii) cellulose, starch and pullulan (Jaschinski, Gunnars, Besemer, \& Bragd, 2001; Jetten, van den Dool, van Hartingsveldt, \& van Wandelen, 2000), (iii) cellulose nanofibers (Jaušovec, Vogrinčič, \& Kokol, 2015) or galactomannan (Campia et al., 2017; Lavazza et al., 2011; Merlini et al., 2015; Rossi et al., 2016). According to the latter authors, the use of laccase from $T$. versicolor allowed a ten-fold increase in viscosity of the oxidized solution, changing the rheological profile from a viscous behavior to an elastic gel (Lavazza et al., 2011). The formation of new inter-chain hemiacetalic bonds between carbonyl and hydroxyl groups should be involved in this modification. Merlini et al. (2015) obtained the same kind of results on galactomannans extracted from the seeds of various leguminous plants, e. g. Ceratonia siliqua, Cyamopsis tetragonolobus or Trigonella foenum-graecum. The freeze-drying of the hydrogels obtained following this procedure led to highly water-insoluble and mechanically reinforced polysaccharide aerogels (Rossi et al., 2016). These materials are capable to uptake aqueous or organic solvents over 20 times their own weight, and to absorb and release active biomolecules, suggesting their possible use as safe delivery systems.

Coseri and co-authors reported that $\mathrm{N}$-hydroxyphthalimide (NHPI) and other nonpersistent nitroxyl radical precursors, were suitable catalysts for the selective oxidation of cellulose fibers promoted by the $\mathrm{NaClO} / \mathrm{NaBr}$ system (Biliuta, Fras, Strnad, Harabagiu, \& Coseri, 2010; Coseri, Nistor, Fras, Strnad, Harabagiu, \& Simionescu, 2009).

The proposed mechanism implies the formation of the corresponding phthalimide- $N$-oxyl (PINO) radical (Recupero \& Punta, 2007; Melone \& Punta, 2013). The latter is oxidized to the corresponding $N$-oxammonium cation, which in turn is responsible for the oxidation of the $\mathrm{C} 6$ alcoholic function. By a comparison on the effect of TEMPO and PINO radicals on cellulose oxidation, the NHPI oxidation mediator resulted to afford the highest conversion in carboxylic groups and to better preserve the morphology and the molecular weight of the starting material (Biliuta et al., 2013). 


\section{TEMPO-mediated oxidized polysaccharides: for what purpose?}

\subsection{Uses and applications of TOCNFs}

Due to their specific mechanical, chemical, and physical properties, TOCNFs have found, in the last decade, more sophisticated applications compared to other polysaccharides, in fields ranging from biomedicine to energy, to sensing, as well as to environmental remediation (Isogai et al., 2011).

Nanofibrils obtained by this oxidative procedure can be either used as additives for specific formulations, or nanostructured in films, hydrogels, and aerogels for advanced applications, with or without the addition of cross-linkers.

The reasons for this significant versatility is mainly laid on a direct consequence of the oxidative process, which implies a selective introduction of carboxylic functionalities in the backbone of the polysaccharide. Carboxylic groups play at least three different roles. They favor the defibrillation of cellulose at basic $\mathrm{pH}$, by electrostatic repulsion of the negatively charged cellulose chains. Moreover, carboxylic groups can be involved in the cross-linking process of the fibrils, either by promoting the formation of intermolecular hydrogen bonding with other polysaccharide chains, or by favoring the formation of composites via ionic-electrostatic interactions or the formation of covalent bonds.

Finally, carboxylic moieties can also represent ideal hooks for further grafting of the carbohydrate with active molecules, widening the chemical and physical properties of the material. In this context, Orelma et al. (2016) have recently reported the preparation of photoreactive nanocellulosic films via a four step protocol, i.e. (i) TEMPO-mediated oxidation; (ii) grafting with amino-benzophenone, by promoting the formation of amide bonds between the carboxylic functions of the fibrils and the amino groups of the aromatic compound; (iii) defibrillation using high pressure fluidization; (iv) cross-linking by activating free-radical reactions with UV radiation. The final materials show enhanced mechanical properties. In this section we present an admittedly partial selection of recently reported original applications of TOCNFs.

\subsubsection{Direct use of TOCNFs}

The use of TOCNFs as green additives is mainly associated to the possibility of modulating the final mechanical properties of the material.

The addition of TOCNFs in adhesives guarantees, for example, a reinforcement for waterborne polyurethane coatings on wood, also improving the pencil hardness of the coating (Cheng, Wen, An, Zhu, $\& \mathrm{Ni}, 2016)$. However, this is at the expense of the surface roughness and adhesion strength of the coating to the wood surface, which are both negatively affected.

TOCNFs derived from bacterial cellulose are also valuable, safe, and biodegradable alternatives to standard surfactants for the stabilization of oil/water interface in emulsions. Their enhanced efficiency, compared to the corresponding non-oxidized fibrils, is probably due both to the lower size of TOCNFs and to their increased hydrophilicity, with a consequent lower contact angle (Jia et al., 2016). This study highlights how the long-term stability of the emulsions derives from an optimal compromise among different factors, namely the fibril dosage, size and wettability.

The chemical-physical properties of TOCNFs have also suggested their use for the design of high-performance batteries. They are candidates to be ideal binders for flexible Li-ion batteries in future flexible electronic devices, playing an important role in the fabrication of electrodes by holding together active and conductive materials together (Lu, Behm, Leijonmarck, Lindbergh, \& Cornell, 2016). While there are several examples reporting the use of non-oxidized cellulose nanofibrils for this purpose, TOCNFs show the advantage of preventing common aggregation of fibrils, usually due to formation of hydrogen bonds between hydroxyl groups.

Moreover, TOCNFs have also been used as starting materials for the production, by thermal carbonization, of hard carbon anodes in Na-ion batteries (Shen et al., 2015). The experiments emphasized how the pretreatment with the oxidation protocol could affect the porosity of the final carbon, significantly decreasing the specific surface area of the resulting material, if compared to that obtained starting from pristine wood fibrils $\left(126 \mathrm{~m}^{2} \mathrm{~g}^{-1}\right.$ versus $586 \mathrm{~m}^{2} \mathrm{~g}^{-1}$, respectively). The low surface area carbon resulted in a higher initial Coulombic efficiency, when used as an anode for Na-ion batteries.

Finally, TOCNFs can also behave as efficient nanocarriers for bioactive molecules reversibly immobilized on fibrils by electrostatic interaction (Weishaupt et al., 2015)

\subsubsection{Self-assembled TOCNFs}

Self-assembled nanostructured materials derived from milky suspensions of TOCNFs can be obtained in different forms, such as films, powders, and aerogels, by simply varying the methods applied to achieve the final purpose (air-, spray-, freeze-, or supercritically-drying) (Jiang \& Hsieh, 2013a, 2013b; Peng, Gardner, \& Han, 2012). Self-assembling is also highly affected by the protonation degree of the carboxylic groups, with a consequent different behavior in the interaction with solvents as a function of their polarity (Jiang \& Hsieh, 2016).

Air-drying of fully protonated TOCNFs leads to formation of films due to the interfibrillar hydrogen bonding. These films show high oxygen and hydrogen permeability and low water adsorption (Fukuzumi, Fujisawa, Saito, \& Isogai, 2013; Fujisawa, Okita, Fukuzumi, Saito, \& Isogai, 2011). Moreover, the preliminary immobilization of proteins via classical coupling chemistry ( $N$-hydroxysuccinimide/1-ethyl-3-[3(dimethylamino)propyl]carbodiimide) (EDA) provides films with enhanced and specific bioactivity (Arola, Tammelin, Setälä, Tullila, \& Linder, 2012; Orelma, Johansson, Filpponen, Rojas, \& Laine, 2012).

The alternative approach of freeze-drying, for the treatment of TOCNFs aqueous suspensions, leads to the formation of highly porous aerogels. Among the several possible applications, these scaffolds can be considered ideal templates for further coating, in order to confer to the material new specific properties. In this context, we have reported a simple protocol to obtain hybrid organic-ceramic aerogels by simply mixing TOCNFs aqueous hydrogels with $\mathrm{TiO}_{2} / \mathrm{SiO}_{2}$ sols, followed by freeze-drying of the resulting mixture (Melone et al., 2013). Calcination of the obtained material, and further heating up to $800^{\circ} \mathrm{C}$, led to formation of ceramic aerogels with a high specific surface area, capable of combining a high adsorption efficiency for organic molecules with photocatalytic activity under UV radiation (Fig. 6a). Thanks to this property, the system was successfully tested in the photo-degradation of Methylene blue and Rhodamine B dyes, as representative examples of organic pollutants. More recently, Panzella et al. (2016) have verified the possibility to conduct a surface functionalization of TOCNF aerogels by ammonia induced solid state eumelanin coating, via polymerization of 5,6-dihydroxyindole (DHI), previously deposited from an organic solution. The new all-natural aerogel biomaterial, whose porosity was not affected by the coating treatment, showed a potent antioxidant activity, an enhanced adsorption capacity towards organic dyes, and an interesting hydrophobic behavior (Fig. 6b).

\subsubsection{TOCNF composites}

The formulation of TOCNF in composites probably represents the favorite route, followed by research groups operating in this field, to provide advanced high-performing materials. 


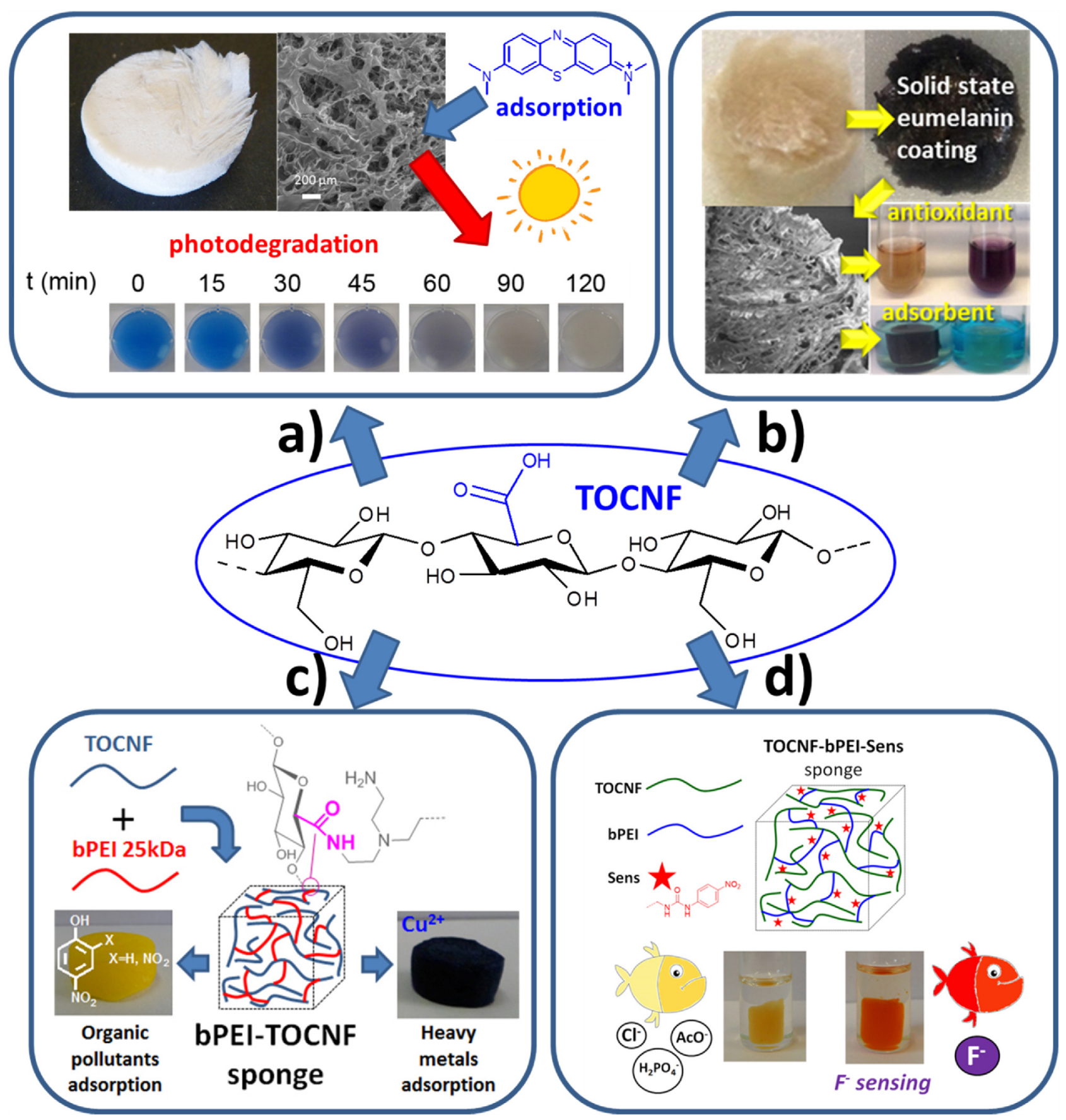

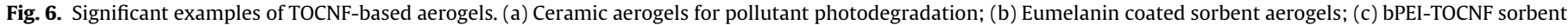
aerogels for environmental remediation; (d) Functionalized bPEI-TOCNF sorbent aerogels for sensing.

The presence of negatively charged carboxylates on the backbone of cellulose nano- and micro-fibrils suggested the possibility of preparing microgels and nanogels by ionic-ionic interactions with cations (Masruchin, Park, Causin, \& Um, 2015). The trivalent $\mathrm{Al}^{3+}$ provided the strongest ionic cross-linking, promoting the formation of hydrogels which, if compared with those obtained in the presence of cations with lower valency, were characterized by higher stiffness, compressive strength, surface area, and porosity, and a tighter network structure. Nevertheless, the highly porous structure in these nanogels negatively affected the drug-delivery profile from the matrix.

Within the same field of inorganic/organic interactions, TOCNF/molybdenum sulfide composites, prepared by a hydrother- mal method, were proposed as non-enzymatic sensors for the electrocatalytic determination of nitrides via their oxidation in water (Wang et al., 2016).

Above all others, hybrid organic composites provide the most versatility in the design of new materials with enhanced properties. Transparent and printable films can be obtained by mixing the negatively charged TOCNFs with single-walled carbon nanotubes (Koga et al., 2013) or with carbon dots, directly obtained by TOCNFs via heating in microwave oven in the presence of 4,7,10trioxa-1,13-tridecanediamine (Jiang, Zhao, Feng, Fang, \& Shi, 2016). In the first case, the resulting flexible material exhibits highly conductive properties, suggesting the possibility to substitute classical polymers with TOCNFs for the design of electrical devices, while the 
latter hybrid film has a strong blue luminescence under ultraviolet excitation.

Thermally responsive hydrogels (Wei et al., 2016) and aerogels (Zhang, Wang et al., 2016; Zhang, Zang et al., 2016) have been obtained by incorporating TOCNFs in poly( $N$-isopropylacrylamide) matrices. The addition of the oxidized nanofibrils allows to improve their mechanical properties, giving the materials exceptionally high compressive strength.

The presence of carboxylic groups on the backbone structure also suggested the possibility of an efficient ionic/ionic interaction and/or cross-linking with poly-amine polymers. For example, the incorporation of TOCNF's into a chitosan matrix has encouraged the development of completely biobased, flexible, and transparent films for potential applications in food packaging (Soni, Hassan, Shilling, \& Mahmoud, 2016).

In this context, Melone, Bonafede et al. (2015) and Melone, Rossi et al. (2015) have recently reported a thermal route for the production of TOCNFs/branched-polyethyleneimine (bPEI) aerogels, following a freeze-drying protocol. Further heating of the resulting nanostructured materials in oven at $102^{\circ} \mathrm{C}$, favored the high reticulation (cross-linking) into sponge-like, water stable aerogels, by formation of amide bonds between the carboxylic and the amine moieties. The new materials resulted to be highly efficient adsorbent units for water remediation of heavy metals and phenolic derivatives (Fig. 6c). The properties of the aerogels could be also modified by selective functionalization on the amino groups of the cross-linker. As an example, the cross-linking of TOCNFs with bPEI previously functionalized with $\mathrm{pNO}_{2}$-phenyl urea units led to the formation of aerogels which behaved as heterogeneous sensor for fluoride anions in DMSO solution (Melone, Bonafede, Tushi, Punta, \& Cametti, 2015) (Fig. 6d). More recently, cross-linking of TOCNFs with bPEI for $\mathrm{Cu}(\mathrm{II})$ removal was also obtained following a chemical route, by reacting the two polymers in the presence of glutaraldehyde (Zhang, Zang, Shi, Yu, \& Sheng, 2016).

\subsection{Other applications of oxidized oligo- and polysaccharides}

Even if TOCNFs are still probably the most exciting derivatives from TEMPO oxidation of cellulose, this chemistry obviously gave birth to other oligo- and polysaccharides with high potential in pharmaceutic, cosmetic, (etc.) applications. Table 2 gives a non-exhaustive overview of other physico-chemical and biological properties of generated polyelectrolytes from TEMPO chemistry. Obviously, such parameters as the toxicity and biocompatibility are of first interest especially in pharmaceuticals.

\section{Biodegradation and enzymes involved}

Since the early 2000s, the biodegradability of TEMPO-mediated oxidized polysaccharides has been investigated by different approaches based on (i) the use of various enzymatic treatments, (ii) the screening of microorganism strains able to grow on oxidized polysaccharides as sole carbon source and (iii) the identification from these strains of enzymes involved in the oxidized substrate degradation. Although several polysaccharides have been successfully obtained by TEMPO-mediated oxidation (For review see Bragd et al., 2004), the actual knowledge of their biodegradability and the involved enzymatic mechanisms remain as of today restricted to few polyglucuronates among which celluronate (Kato et al., 2002), 6-oxichitin or chituronic acid (Kato, Kaminaga, Matsuo, \& Isogai, 2004; Kato, Kaminaga, Matsuo, \& Isogai, 2005), amyluronate (Kato et al., 2005), C6-oxidized chitosan (Pierre et al., 2013) and oxidized curdlan (Watanabe, Habu, \& Isogai, 2013).

Susceptibility of celluronic acid sodium salt (celluronate) produced from cellulose oxidation to biodegradation was first investigated using different enzymatic cocktails (Kato et al., 2002) among which the cellulase complex Onozuka R-10 (EC 3.2.1.4), a commercial crude cellulase, has been shown to efficiently decrease the DP (40 times lower after incubation for 40 days) of celluronic acid, involving $\beta$-(1,4)-polyglucuronase enzymatic activity and excluding action of CelloBioHydrolase I (CBH I) (EC 3.2.1.91) and EndoGlucanase II (EGII) (EC 3.2.1.4). The same authors highlighted the higher biodegradability of celluronate using microorganisms in soil samples collected from natural environment, compared to CarboxylMethyl Cellulose (CMC) and amyluronic acid (Kato et al., 2005). Thorough investigations carried out on the bacterial soil Brevundimonas sp. SH203, led to the purification and characterization of two CellUronate Lyase (CUL) (EC 4.2.2.14), CUL-I and CUL-II involved in the $\beta$-1,4-linked polyglucuronate degradation (Konno, Habu, Iihashi, \& Isogai, 2008; Konno, Habu, Maeda, Azuma, \& Isogai, 2006). CUL-I and CUL-II were identified as monomeric proteins with a molecular mass of $37 \mathrm{kDa}$ and $56 \mathrm{kDa}$, respectively, showing high substrate-specificity for celluronate. The authors also observed a relatively weak activity for amyluronate and alginate for CUL-I. While CUL-I was demonstrated to depolymerize celluronate endolytically by $\beta$-elimination to dimeric and monomeric uronates via oligo-celluronate intermediates production, CUL-II was shown to act like an exo-type lyase exhibiting a higher activity on satured and unsatured celluronate dimeric substrates than on celluronate polymers. These observations suggest a synergistic action of CULI and CUL-II in complete degradation of celluronate to monomer residues (Konno et al., 2008). Besides, a Glucuronan Lyase (GL) (29 kDa) (EC 4.2.2.14), isolated from Trichoderma strain GL2, was also described for its ability to depolymerize oxidized cellulose in an endolytic manner to generate dimeric and trimeric oligosaccharides (Delattre, Michaud, Elboutachfaiti, Courtois, \& Courtois, 2006; Konno et al., 2008).

Although amyluronate constitutes an artificial homopolymer ( $\alpha$-1,4-linked polyglucuronate) obtained from starch C6-oxidation, it was found to be biodegradable with a degradation rate lower than celluronate (Kato et al., 2005). Two AmylUronate Hydrolase (AUH) (EC 3.2.1.139) designated as AUH-I and AUH-II have been isolated from Paenibacillus sp. (Iihashi, Nagayama, Habu, Konno, \& Isogai, 2009). AUH-I, a $115 \mathrm{kDa}$ protein, was shown to be highly specific for amyluronate and inert on starch and CMC substrates. The degradation of amyluronate by AUH-I led to glucuronate as main product, indicating an exolytic activity and leading to classify AUH-I as $\alpha-$ glucuronidase. AUH-II protein is still for its part under investigation, but preliminary studies suggested an endolytic activity of AUH-II.

Recent works by Watanabe et al. (2013) allowed selecting Paenibaccillus sp. Strain EH621 growing on TEMPO-mediated oxidized curdlan as sole carbon source. A total carbon reduction $(\sim 60 \%)$ in culture supernatant was obtained within 3 days, indicating the production of enzyme degrading $\beta$-(1,3)-polyglucuronates. Analyses of degradation products led the authors to conclude that endolytic and probably exolytic enzymes were involved in oxidized curdlan depolymerization, with a substrate-specificity restricted to $\beta$-(1,3)polyglucuronates (Watanabe et al., 2013).

The knowledge of chituronic acid biodegradability is restricted to the studies carried out by Kato et al. (2004, 2005), in which the degree of biodegradation of chituronic acid was shown to be close to that of celluluronate and chitin with degree of $\mathrm{N}$-acetylation of $91 \%$. More recently, the biodegradation of C6-oxidized chitosan was shown to be partially effective using various enzymes, already known for their hydrolytic activities on chitosan (Pierre et al., 2013). Notably, Glucanex ${ }^{\circledR}$, composed of cellulose (EC 3.2.1.4), $\beta$ glucanase (EC 3.2.1.6) and chitinase (EC 3.2.1.14), and enzymatic mix from $T$. reesei (EMTR), including chitinase, cellulase and probably a C6-oxichitosanase, led to higher depolymerization level with a final hydrolysis yield close to $20.3 \%$ and $36.4 \%$, while pectinase activity (EC 3.2.1.15) present in Macerozyme R-10 ${ }^{\circledR}$ showed lower 
Table 2

Other generated polyelectrolytes from TEMPO chemistry of polysaccharides and their physico-chemical and biological properties.

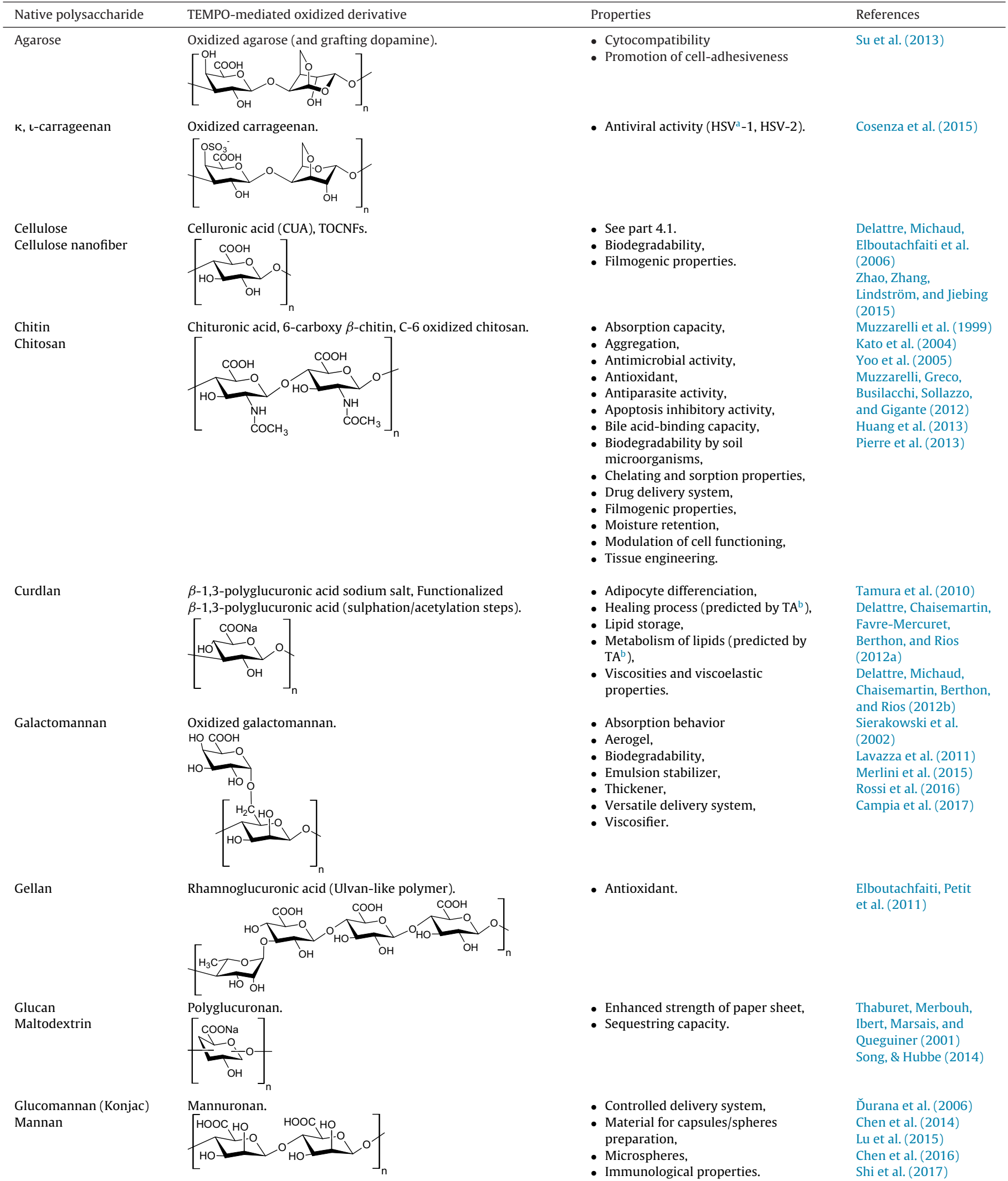


Table 2 (Continued)

\begin{tabular}{|c|c|c|c|}
\hline Native polysaccharide & TEMPO-mediated oxidized derivative & Properties & References \\
\hline Pullulan & $\begin{array}{l}\text { Oxidized pullulan, oxypullulan Functionalized oxidized } \\
\text { pullulan }\end{array}$ & $\begin{array}{l}\text { - Injectable hydrogel to prevent tissue } \\
\text { adhesion, } \\
\text { - Reducing and capping agents, } \\
\text { - Rheological behavior, } \\
\text { - Surfactant properties. }\end{array}$ & $\begin{array}{l}\text { Pereira et al. (2014) } \\
\text { Spatareanu et al. } \\
\text { (2014) } \\
\text { Coseri et al. (2015) } \\
\text { Bang, Lee, Ko, Kim, and } \\
\text { Kwon (2016) }\end{array}$ \\
\hline Starch & Oxidized starch Functionalized oxidized starch & $\begin{array}{l}\text { - Controlled delivery system, } \\
\text { - Hydrogels and microgels, } \\
\text { - Microspheres. }\end{array}$ & $\begin{array}{l}\text { Li et al. (2009) } \\
\text { Li et al. (2010) } \\
\text { Li et al. (2011) } \\
\text { Wang et al. (2015) }\end{array}$ \\
\hline Xanthan & Xanthuronan & $\begin{array}{l}\text { - Antioxidant, } \\
\text { - Highly resistant derivative to } \\
\text { enzymes degradation. }\end{array}$ & Delattre et al. (2015) \\
\hline
\end{tabular}

\footnotetext{
a HSV: Herpes Simplex Virus.
}

b TA: Transcriptomic Analysis.

but significant activity. Surprisingly, Glucanex ${ }^{\circledR}$ and EMTR activities on degradation might not involve cellulase as shown by the relatively low level of depolymerization obtained with endo and exo-cellulase mixture (Celluclast ${ }^{\circledR}$ ) (EC 3.2.1.4).

Galactomannans are high molecular weight polysaccharides found mostly in the seeds of leguminous plants. Among the different approaches to galactomannans oxidation reported in the literature (Delagrave et al., 2001, 2002; Hall \& Yalpani, 1980; Mikkonen et al., 2014; Parikka et al., 2010, 2012), the use of TEMPO mediated oxidation or Laccase-Mediator System (LMS)TEMPO system was shown to selectively oxidize primary hydroxyl groups of Guar Gum (GG) as reported in part 3 (Lavazza et al., 2011; Sakakibara et al., 2016; Sierakowski, Freitas, Fujimoto, \& Petri, 2002; Sierakowski et al., 2000; Souza, Lucyszyn, Ferraz, \& Sierakowski, 2011). The biodegradability of oxidized galactomannan by LMS was investigated for two galactomannans, GG and FenuGreek (FG) for which it has been observed a significant sensitivity to $\beta$-mannanase ( $130 \mathrm{mU} / \mathrm{g}_{\mathrm{GM}}$ ) (EC 3.2.1.78) as demonstrated for both oxidized GG and FG by a gradual loss of gel viscosity (Merlini et al., 2015; Rossi et al., 2016). Although depolymerization kinetics estimated by the measure of viscosity decrease during $\beta$-mannanase treatment, appeared different between native and oxidized GG and FG, the viscosity reached a similar value after $24 \mathrm{~h}$ $(\sim 200 \mathrm{mPa}$ ) indicating the capacity of oxidized galactomannan to be biodegraded with various kinetics depending of their source.

Others TEMPO-mediated oxidized polysaccharides, such as xanthan and xyloglucan, were also analysed for their biodegradability (Delattre et al., 2015; Takeda, Miller, \& Fry, 2008), but in both cases, xanthuronate and oxidized-xyloglycan were demonstrated to be highly resistant to enzymatic hydrolysis, in particular to classical commercial cellulases (Macerozyme R-10 ${ }^{\circledR}$, Celluclast ${ }^{\circledR}$ ), hyaluronidase (EC 3.2.1.35) and alginate lyase (EC 4.2.2.3) for xanthuronate, and to endo-(1,4)- $\beta$-glucanase (EC 3.2.1.4) concerning oxidized-xyloglycan.

Overall, the need to understand enzymatic mechanisms involved in oxidized polysaccharides degradation is stimulated by the high potential for valorization and applications of byproducts (i.e. oliguronates) in pharmaceutical, cosmetic and non food industries. The biodegradability of TEMPO-mediated oxidized polysaccharides was clearly demonstrated for few polysaccharides (celluronate, amyluronates, C6-oxidized chitosan and chituronic acid) and for some of them involved enzymes belonging to glucuronate lyases and hydrolases. A better knowledge of enzymes involved in C6-oxidized polysaccharides degradation remain essential and could contribute to the development of performing molecular tools, notably by engineering genetics, able to produce valorizing oliguronates.

\section{Conclusion}

The oxidation of polysaccharides using TEMPO chemistry have been abundantly published since the nineties and results have clearly led to a significant increase of knowledge on the biological and physico-chemical properties of polyuronides, mostly on oxidized celluloses. However, several publications offer very optimistic and sometimes utopian conclusions. Starting with the first work of de Nooy et al. (1994), no real industrial developments on a large scale have materialized on TEMPO oxidized polysaccharides, in spite of numerous filed patents. The main reason for this relatively meager industrial success is probably the same as for other natural polysaccharides from various sources (microorganisms, terrestrial plants and macroalgae). The costs and technologies 
required for their production can hardly compete with some natural or modified polysaccharides with low production costs and already well positioned in their market. The main issue for oxidized polysaccharides is to find a free technological and high value niche. In this context, it will be very difficult for TEMPO oxidized celluloses to compete with some cellulosic derivatives such as carboxymethyl cellulose, hydroxyethyl cellulose and others. The example of low commercial success of the bacterial glucuronan from a Sinorhizobium meliloti strain (Elboutachfaiti, Delattre et al., 2011; Elboutachfaiti, Petit et al., 2011) perfectly supports this proposition. Firstly published in 1993, the bacterial oxidized cellulose called glucuronan only found applications in the cosmetic field for its biological property despite its interesting rheological behavior. This pessimistic interpretation could easily change for the better in the future considering the current developments of oxidized cellulose in the material field, the potential of TEMPO oxidized polygalactomannan as delivery system of actives, but also the identification of the biodegradability of TEMPO oxidized polysaccharides. The biodegradability leads to a fundamental question about the role of these enzymes in nature, indicating the presence of natural polyuronides, maybe not yet discovered, and/or the existence of substrates having structural analogies with TEMPO oxidized polysaccharides.

\section{Acknowledgements}

This work has been sponsored by (i) Cariplo Foundation (grant 2014-0478), (ii) Regione Toscana (POR FESR 2014-2020, Call RSI 2014, Project NanoBonD), (iii) Regione Lombardia (RL-INSTM Call 20016, Project NAIADI), (iv) the French government research program "Investissements d'avenir" through the IMobS3 Laboratory of Excellence (ANR-10-LABX-16-01), (v) the European Union through the program Regional competitiveness and employment 20142020 (ERDF-Auvergne region).

\section{References}

Adam, W., Saha-Möller, C. R., \& Ganeshpure, P. A. (2001). Synthetic applications of non metal catalysts for homogeneous oxidations. Chemical Reviews, 101(11), 3499-3548.

Anelli, P. L., Banfi, C., Montanari, F., \& Quici, S. (1987). Fast and selective oxidation of primary alcohols to aldehydes or to carboxylic acids and of secondary alcohols to ketones mediated by oxoammonium salts under two-phase conditions. Journal of Organic Chemistry, 52(12), 2559-2562.

Anelli, P. L., Banfi, S., Montanari, F., \& Quici, S. (1989). Oxidation of diols with alkal hypochlorites catalyzed by oxammonium salts under two-phase conditions. Journal of Organic Chemistry, 54(12), 2970-2972.

Arola, S., Tammelin, T., Setälä, H., Tullila, A., \& Linder, M. B. (2012). Immobilization-stabilization of proteins on nanofibrillated cellulose derivatives and their bioactive film formation. Biomacromolecules, 13, 594-603.

Aspinall, G. O., \& Nicolson, A. (1960). The catalytic oxidation of European larch I $\mu$-galactan. Journal of Chemical Society, 2503-2507.

Bailey, W. F., Bobbitt, J. M., \& Wiberg, K. B. (2007). Mechanism of the oxidation of alcohols by oxoammonium cations. Journal of Organic Chemistry, 72(12) 4504-4509.

Bang, S., Lee, E., Ko, Y.-G., Kim, W. I., \& Kwon, O. H. (2016). Injectable pullulan hydrogel for the prevention of postoperative tissue adhesion. International Journal of Biological Macromolecules, 87, 155-162.

Biliuta, G., Fras, L., Strnad, S., Harabagiu, V., \& Coseri, S. (2010). Oxidation of cellulose fibers mediated by nonpersistent nitroxyl radicals. Journal of Polymer Science, Part A: Polymer Chemistry, 48, 4790-4799.

Biliuta, G., Fras, L., Drobota, M., Persin, Z., Kreze, T., Stana-Kleinschek, K., et al. (2013). Comparison study of TEMPO and phthalimide-N-oxyl (PINO) radicals on oxidation efficiency toward cellulose. Carbohydrate Polymers, 91, 502-507.

Bobbitt, J. M., \& Flores, M. C. L. (1988). Organic nitrosonium salts as oxidants in organic chemistry. Heterocycles, 27(2), 509-533

Bordenave, N., Grelier, S., \& Coma, V. (2008). Advances on selective C-6 oxidation of chitosan by TEMPO. Biomacromolecules, 9, 2377-2382

Bragd, P. L., Besemer, A. C., \& van Bekkum, H. (2002). Selective oxidation of carbohydrates by 4-AcNH-TEMPO/peracid systems. Carbohydrate Polymers, 49 397-406.

Bragd, P. L., Van Bekkum, H., \& Besemer, A. C. (2004). TEMPO-mediated oxidation of polysacharrides: Survey of methods and applications. Topics in Catalysis, 27. 49-66.
Campia, P., Ponzini, E., Rossi, B., Farris, S., Silvetti, T., Merlini, L., et al. (2017). Aerogels of enzymatically oxidized galactomannans from leguminous plants: Versatile delivery systems of antimicrobial peptides and enzymes. Carbohydrate Polymers, 158, 102-111. http://dx.doi.org/10.1016/j.carbpol. 2016.11.089

Camy, S., Montanari, S., Rattaz, A., Vignon, M., \& Condoret, J. S. (2009). Oxidation of cellulose in pressurized carbon dioxide. The Journal of Supercritical Fluids, 51, 188-196.

Caron, S., Dugger, R. W., Ruggeri, S. G., Ragan, J. A., \& Brown Ripin, D. H. (2006). Large-scale oxidations in the pharmaceutical industry. Chemical Reviews, 106(7), 2943-2989.

Cella, J. A., Kelley, J. A., \& Kenehan, E. F. (1975). Nitroxide-catalyzed oxidation of alcohols using m-chloroperbenzoic acid. New method. The Journal of Organic Chemistry, 40(12), 1860-1862.

Chang, P. S., \& Robyt, J. F. (1996). Oxidation of primary alcohol groups of naturally occurring polysaccharides with 2,2,6,6-tetramethyl-1-piperidine oxoammonium ion. Journal of Carbohydrate Chemistry, 15, 819-830.

Chen, X., Xang, S., Lu, M., Chen, Y., Zhao, L., Li, W., et al. (2014). Formation and characterization of light-responsive TEMPO-oxidized konjac glucomannan microspheres. Biomacromolecules, 15, 2166-2171.

Chen, Y., Zhao, H., Liu, X., Li, Z., Liu, B., Wu, J., et al. (2016). TEMPO-oxidized Konjac glucomannan as appliance for the preparation of hard capsules. Carbohydrate Polymers, 143, 262-269.

Cheng, D., Wen, Y., An, X., Zhu, X., \& Ni, Y. (2016). TEMPO-oxidized cellulose nanofibers (TOCNs) as a green reinforcement for waterborne polyurethane coating (WPU) on wood. Carbohydrate Polymers, 151, 326-334.

Ciriminna, R., \& Pagliaro, M. (2010). Industrial oxidations with organocatalyst TEMPO and its derivatives. Organic Process Research and Development, 14(1), 245-251.

Cosenza, V. A., Navarro, D. A., Pujol, C. A., Damonte, E. B., \& Stortz, C. A. (2015). Partial and total C-6 oxidation of gelling carrageenans: Modulation of the antiviral activity with the anionic character. Carbohydrate Polymers, 128, 199-206.

Coseri, S., Nistor, G., Fras, L., Strnad, S., Harabagiu, V., \& Simionescu, B. C. (2009). Mild and selective oxidation of cellulose fibers in the presence of N-hydroxyphthalimid. Biomacromolecules, 10, 2294-2299.

Coseri, S., Spatareanu, A., Sacarescu, L., Rimbu, C., Suteu, D., Spirk, S., et al. (2015). Green synthesis of the silver nanoparticles mediated by pullulan and 6-carboxypullulan. Carbohydrate Polymers, 116, 9-17.

Coseri, S., Bercea, M., Harabagiu, V., \& Budtova, T. (2016). Oxidation vs. degradation in polysaccharides: Pullulan-a case study. European Polymers Journal, 85, $82-91$.

Cunha, P. L. R., Maciel, J. S., Sierakowski, M. R., de Paula, R. C. M., \& Feitosa, J. P. A. (2007). Oxidation of cashew tree gum exudates polysaccharide with TEMPO reagent. Journal of the Brazilian Chemical Society, 18, 85-92.

Davis, N. J., \& Flitsch, S. L. (1993). Selective oxidation of monosaccharide derivatives to uronic acids. Tetrahedron Letters, 34, 1181-1184.

DeAngelis, P. L. (2012). Glycosaminoglycan polysaccharide biosynthesis and production: Today and tomorrow. Applied Microbiology and Biotechnology, 94 295-305.

Delagrave, S., Murphy, D. J., Rittenhouse Pruss, J. L., Maffia, A. M., III, Marrs, B. L., Bylina, E. J., et al. (2001). Application of a very high-throughput digital imaging screen to evolve the enzyme galactose oxidase. Protein Engineering, 14, 261-267.

Delagrave, S., Maffia III, A. M., Murphy, D. J., Rittenhouse Pruss, J. L., Bylina, E. J., \& Coleman, W. J. (2002). Variant galactose oxidase nucleic acid encoding same, and methods of using same. US Patent no. 6.498.026 B2.

Delattre, C., Michaud, P., Elboutachfaiti, R., Courtois, B., \& Courtois, J. (2006). Production of oligocellouronates by biodegradation of oxidized cellulose. Cellulose, 13, 63-71.

Delattre, C., Michaud, P., Keller, C., Elboutachfaiti, R., Beven, L., Courtois, B., et al. (2006). Purification, characterization and biological properties of a novel polysaccharide lyase from Trichoderma sp. GL2. Applied Microbiology and Biotechnology, 70, 437-443.

Delattre, C., Rios, L., Laroche, C., Le, N. H. T., Lecerf, D., Picton, L., et al. (2009). Production and characterization of new families of polyglucuronic acids from TEMPO-NaOCl oxidation of curdlan. International Journal of Biological Macromolecules, 45, 458-462.

Delattre, C., Chaisemartin, L., Favre-Mercuret, M., Berthon, J. Y., \& Rios, L. (2012). Biological effect of $\beta-(1,3)$-polyglucuronic acid sodium salt on lipid storage and adipocytes differenciation. Carbohydrate Polymers, 87, 775-783.

Delattre, C., Michaud, P., Chaisemartin, L., Berthon, J. Y., \& Rios, L. A. (2012). A transcriptomic approach to predict the impact of $\beta-(1,3)$-polyglucuronic acid sodium salt and derivatives in the main biological processes. Carbohydrate Polymers, 87, 1828-1836.

Delattre, C., Pierre, G., Gardarin, C., Traikia, M., Elboutachfaiti, R., Isogai, A., et al (2015). Antioxidant activities of a polyglucuronic acid sodium salt obtained from TEMPO-mediated oxidation of xanthan. Carbohydrate Polymers, 116 34-41.

de Nooy, A. E. J., Besemer, A. C., \& van Bekkum, H. (1994). Highly selective TEMPO mediated oxidation of primary alcohol groups in polysaccharides. Recueil des Travaux Chimiques des Pays-Bas, 113, 165-166.

de Nooy, A. E. J., Besemer, A. C., \& van Bekkum, H. (1995a). Highly selective nitroxyl radical-mediated oxidation of primary alcohol groups in water soluble glucans. Carbohydrate Research, 269, 89-98. 
de Nooy, A. E. J., Besemer, A. C., \& van Bekkum, H. (1995b). Selective oxidation of primary alcohols mediated by nitroxyl radical in aqueous solution. Kinetics and mechanisms. Tetrahedron, 51, 8023-8032.

De Nooy, A. E. J., Besemer, A. C., van Bekkum, H., van Dijk, J. A. P. P., \& Smit, J. A. M. (1996). TEMPO mediated oxidation of pullulan and influence of ionic strength and linear charge density on the dimensions of the obtained polyelectrolyte chains. Macromolecules, 29.

Ďurana, R., Lacík, I., Paulovičová, E., \& Bystrický, S. (2006). Functionalization of mannans from pathogenic yeasts by different means of oxidation-preparation of precursors for conjugation reactions with respect to preservation of immunological properties. Carbohydrate Polymers, 63, 72-81.

Elboutachfaiti, R., Petit, E., Beuvain, C., Courtois, B., Courtois, J., \& Delattre, C. (2010). Development of new ulvan-like polymer by regioselective oxidation of gellan exopolysaccharide using TEMPO reagent. Carbohydrate Polymers, 80, 485-490.

Elboutachfaiti, R., Delattre, C., Petit, E., \& Michaud, P. (2011). Polyglucuronic acids: Structures, functions and degrading enzymes. Carbohydrate Polymers, 84, 1-13.

Elboutachfaiti, R., Petit, E., Pillon, M., Courtois, B., Courtois, J., \& Delattre, C. (2011). Evaluation of antioxidant capacity of ulvan-like polymer obtained by regioselective oxidation of gellan exopolysaccharide. Food Chemistry, 127, 976-983.

Fujisawa, S., Okita, Y., Fukuzumi, H., Saito, T., \& Isogai, A. (2011). Preparation and characterization of TEMPO-oxidized cellulose nanofibril films with free carboxyl groups. Carbohydrate Polymers, 84(1), 579-583.

Fukuzumi, H., Fujisawa, S., Saito, T., \& Isogai, A. (2013). Selective permeation of hydrogen gas using cellulose nanofibril film. Biomacromolecules, 14(5), 1705-1709.

Golubev, V. A., Rozantsev, E. G., \& Neiman, M. B. (1966). Some reactions of free iminoxyl radicals with the participation of the unpaired electron Bulletin of the Academy of Sciences. USSR Division of Chemical Science, 14(11), 1898-1904.

Hall, L. D., \& Yalpani, M. (1980). A high-yielding, specific method for the chemical derivatization of D-galactose-containing polysaccharides: Oxidation with d-galactose oxidase, followed by reductive amination. Carbohydrate Research, $81,10-12$.

Hiraoki, R., Fukuzumi, H., Ono, Y., Saito, T., \& Isogai, A. (2014). SEC-MALLS analysis of TEMPO-oxidized celluloses using methylation of carboxyl groups. Cellulose, $21,167-176$

Hirota, M., Tamura, N., Saito, T., \& Isogai, A. (2009). Oxidation of regenerated cellulose with $\mathrm{NaClO}_{2}$ catalyzed by TEMPO and NaClO under acid-neutral conditions. Carbohydrate Polymers, 78, 330-335.

Huang, J., Chen, W.-W., Hu, S., Gong, J.-Y., Lai, H.-W., Liu, P., et al. (2013). Biochemical activities of 6 -carboxy $\beta$-chitin derived from squid pens. Carbohydrate Polymers, 91, 191-197.

Iihashi, N., Nagayama, J., Habu, N., Konno, N., \& Isogai, A. (2009). Enzymatic degradation of amylouronate $(\alpha-(1 \rightarrow 4)$-linked glucuronan $)$ by $\alpha$-glucuronidase from Paenibacillus sp. TH501b. Carbohydrate Polymers, 77, $59-64$

Isogai, A., \& Kato, Y. (1998). Preparation of polyuronic acid from cellulose by TEMPO-mediated oxidation. Cellulose, 5, 153-164.

Isogai, T., Saito, T., \& Isogai, A. (2010). TEMPO electromediated oxidation of some polysaccharides including regenerated cellulose fiber. Biomacromolecules, 11, 1593-1599.

Isogai, A., Saito, T., \& Fukuzumi, H. (2011). TEMPO-oxidized cellulose nanofibers. Nanoscale, 3, 71-85.

Jaschinski, T., Gunnars, S., Besemer, A. C., \& Bragd, P. (2001). WO Patent 01/034656.

Jaušovec, D., Vogrinčič, R., \& Kokol, V. (2015). Introduction of aldehyde vs. carboxylic groups to cellulose nanofibers using laccase/TEMPO mediated oxidation. Carbohydrate Polymers, 116, 74-85.

Jetten, J. M., van den Dool, R. T. M., van Hartinggsveldt, W., \& van Wandelen, M. (2000). WO Patent 00/50621.

Jia, Y., Zhai, X., Fu, W., Liu, Y., Li, F., \& Zhong, C. (2016). Surfactant-free emulsions stabilized by tempo-oxidized bacterial cellulose. Carbohydrate Polymers, 151, 907-915.

Jiang, F., \& Hsieh, Y.-L. (2013a). Super water absorbing and shape memory nanocellulose aerogels from TEMPO-oxidized cellulose nanofibrils via cyclic freezing-thawing. Journal of Material Chemistry A, 2(2), 350-359.

Jiang, F., \& Hsieh, Y.-L. (2013b). Chemically and mechanically isolated nanocellulose and their self-assembled structures. Carbohydrate Polymers, 95(1), 32-40.

Jiang, F., \& Hsieh, Y.-L. (2016). Self-assembling of TEMPO oxidized cellulose nanofibrils As affected by protonation of surface carboxyls and drying methods. ACS Sustainable Chemistry and Engineering, 4, 1041-1049.

Jiang, B., Drouet, E., Milas, M., \& Rinaudo, M. (2000). Study on TEMPO-mediated selective oxidation of hyaluronan and the effects of salt on the reaction kinetics. Carbohydrate Polymers, 327, 455-461.

Jiang, Y., Zhao, Y., Feng, X., Fang, J., \& Shi, L. (2016). TEMPO-mediated oxidized nanocellulose incorporating with its derivatives of carbon dots for luminescent hybrid films. RSC Advances, 6, 6504-6510.

Kato, Y., Habu, N., Yamaguchi, J., Kobayashi, Y., Shibata, I., Isogai, A., et al. (2002). Biodegradation of $\beta-1,4$-linked polyglucuronic acid (cellouronic acid). Cellulose, 9, 75-81.

Kato, Y., Kaminaga, J., Matsuo, R., \& Isogai, A. (2004). TEMPO-mediated oxidation of chitin, regenerated chitin and $\mathrm{N}$-acetylated chitosan. Carbohydrate Polymers, $58,421-426$

Kato, Y., Kaminaga, J. I., Matsuo, R., \& Isogai, A. (2005). Oxygen permeability and biodegradability of polyuronic acids prepared from polysaccharides by TEMPO-mediated oxidation. Journal of Polymers and Environment, 13, 261-266.
Koga, H., Saito, T., Kitaoka, T., Nogi, M., Suganuma, K., \& Isogai, A. (2013). Transparent, conductive, and printable composites consisting of TEMPO-oxidized nanocellulose and carbon nanotube. Biomacromolecules, 14, $1160-1165$.

Konno, N., Habu, N., Maeda, I., Azuma, N., \& Isogai, A. (2006). Cellouronate ( $\beta-1$, 4-linked polyglucuronate) lyase from Brevundimonas sp. SH203: Purification and characterization. Carbohydrate Polymers, 64, 589-596.

Konno, N., Habu, N., Iihashi, N., \& Isogai, A. (2008). Purification and characterization of exo-type cellouronate lyase. Cellulose, 15, 453-463.

Konno, N., Igarashi, K., Habu, N., Samejima, M., \& Isogai, A. (2009). Cloning of the Trichoderma reesei cDNA encoding a glucuronan lyase belonging to a novel polysaccharide lyase family. Applied Environmental Microbiology, 75, 101-107.

Lavazza, M., Formantici, C., Langella, V., Monti, D., Pfeiffer, U., \& Galante, Y. M. (2011). Oxidation of galactomannan by laccase plus TEMPO yields an elactic gel. Journal of Biotechnology, 156, 108-116.

Lee, K. Y., \& Mooney, D. J. (2012). Alginates: Properties and biomedical applications. Progress in Polymer Science, 37, 106-126.

Lemoine, S., Thomazeau, C., Joannard, D., Trombotto, S., Descottes, S., Bouchu, A., et al. (2016). Sucrose tricarboxylate by sonocatalysed TEMPO-mediated oxidation. Carbohydrate Polymers, 16, 176-184.

Li, Y., de Vries, R., Kleijn, M., Slaghek, T., Timmermans, J., Cohen Stuart, M., et al. (2009). Preparation and characterization of oxidized starch polymer microgels for encapsulation and controlled release of functional ingredients. Biomacromolecules, 10, 1931-1938.

Li, Y., de Vries, R., Kleijn, M., Slaghek, T., Timmermans, J., Cohen Stuart, M., et al. (2010). Lysozyme uptake by oxidized starch polymer microgels. Biomacromolecules, 11, 1754-1762.

Li, Y., Zhang, Z., van Leeuwen, H. P., Cohen Stuart, M. A., Norde, W., \& Kleijn, J. M. (2011). Uptake and release kinetics of lysozyme in and from an oxidized starch polymer microgel. Soft Matter, 7, 10377-10385.

Lu, M., Li, Z., Liang, H., Shi, M., Zhao, L., Li, W., et al. (2015). Controlled release of anthocyanins from oxidized konjac glucomannan microspheres stabilized by chitosan oligosaccharides. Food Hydrocolloids, 51, 476-485

Lu, H., Behm, M., Leijonmarck, S., Lindbergh, G., \& Cornell, A. (2016). Flexible paper electrodes for Li-Ion batteries using low amount of TEMPO-oxidized cellulose nanofibrils as binder. Applied Materials and Interfaces, 8, 18097-18106.

Marzorati, M., Danieli, B., Haltrich, D., \& Riva, S. (2005). Selective laccase-mediated oxidation of sugars derivatives. Green Chemistry, 7, 310-315.

Masruchin, N., Park, B.-D., Causin, V., \& Um, I. C. (2015). Characteristics of TEMPO-oxidized cellulose fibril-based hydrogels induced by cationic ions and their properties. Cellulose, 22, 1993-2010.

Mathew, S., \& Adlercreutz, P. (2009). Mediator facilitated, laccase catalysed oxidation of granular potato starch and the physico-chemical characterisation of the oxidized products. Bioresource Technology, 100, 3576-3584.

Maurer, K., \& Reiff, G. (1943). Oxidation of cellulose with $\mathrm{NO}_{2}$. Journal of Macromolecular Chemistry, 1, 27-34

Melone, L., \& Punta, C. (2013). Metal-free aerobic oxidations mediated by $\mathrm{N}$-hydroxyphthalimide: A concise review. Beilstein Journal of Organic Chemistry, 9. 1296-1310.

Melone, L., Altomare, L., Alfieri, I., Lorenzi, A., De Nardo, L., \& Punta, C. (2013). Ceramic aerogels from TEMPO-oxidized cellulose nanofibre templates: Synthesis, characterization, and photocatalytic properties. Journal of Photochemistry and Photobiology A: Chemistry, 261, 53-60.

Melone, L., Bonafede, S., Tushi, D., Punta, C., \& Cametti, M. (2015). Dip in colorimetric fluoride sensing by a chemically engineered polymeric cellulose/bPEI conjugate in the solid state. RSC Advances, 5, 83197-83205.

Melone, L., Rossi, B., Pastori, N., Panzeri, W., Mele, A., \& Punta, C. (2015). TEMPO-oxidized cellulose cross-linked with branched polyethyleneimine: Nanostructured adsorbent sponges for water remediation. ChemPlusChem, 80, $1408-1415$.

Meng, Q., Fu, S., \& Lucia, L. A. (2016). The role of heteropolysaccharides in developing oxidized cellulose nanofibrils. Carbohydrate Polymers, 144 , 187-195

Merlini, L., Boccia, A. C., Mendichi, R., \& Galante, Y. M. (2015). Enzymatic and chemical oxidation of polygalactomannans from the seeds of a few species of leguminous plants and characterization of the oxidized products. Journal of Biotechnology, 198, 31-43.

Mikkonen, K., Parikka, K., Suuronen, J. P., Ghafar, A., Serimaa, R., \& Tenkanen, M. (2014). Enzymatic oxidation as a potential new route to produce polysaccharide aerogels. RSC Advances, 4, 11884-11892.

Muzzarelli, R. A. A., Muzzarelli, C., Cosani, A., \& Terbojevich, M. (1999). 6-Oxychitins, novel hyaluronan-like regiospecifically carboxylated chitins. Carbohydrate Polymers, 39, 361-367.

Muzzarelli, R. A. A., Miliani, M., Cartolari, M., Tarsi, R., Tosi, G., \& Muzzarelli, C. (2000). Polyuronans obtained by regiospecific oxidation of polysaccharides from Aspergillus niger, Trichoderma reesei and Saprolegnia sp. Carbohydrate Polymers, 43, 55-61.

Muzzarelli, R. A. A., Greco, F., Busilacchi, A., Sollazzo, V., \& Gigante, A. (2012). Chitosan, hyaluronan and chondroitin sulfate in tissue engineering for cartilage regeneration: A review. Carbohydrate Polymers, 89, 723-739.

Orelma, H., JFilpponen, L. S., Filpponen, I., Rojas, O. J., \& Laine, J. (2012). Generic method for attaching biomolecules via avidin-biotin complexes immobilized on films of regenerated and nanofibrillar cellulose. Biomacromolecules, 13 , 2802-2810. 
Orelma, H., Vuoriluoto, M., Johansson, L.-S., Campbell, J. M., Ilari Filpponen, I., Biesalski, M., et al. (2016). Preparation of photoreactive nanocellulosic materials via benzophenone grafting. RSC Advances, 6, 85100-85106.

Painter, T. J., Cesaro, A., Delben, F., \& Paoletti, S. (1985). New glucuronoglucans obtained by oxidation of amylose at position 6. Carbohydrate Research, 140, 61-68

Painter, T. J. (1977). Preparation and periodate oxidation of C-6-oxycellulose: Conformational interpretation of hemiacetal stability. Carbohydrate Research, 55, 95-103.

Panzella, L., Melone, L., Pezzella, A., Rossi, B., Pastori, N., Perfetti, M., et al. (2016). Surface-functionalization of nanostructured cellulose aerogels by solid state eumelanin coating. Biomacromolecules, 17(2), 564-571.

Parikka, K., Leppänen, A. S., Pitkänen, L., Reunanen, M., Willför, S., \& Tenkanen, M. (2010). Oxidation of polysaccharides by galactose oxidase. Journal of Agricultural and Food Chemistry, 58, 262-271.

Parikka, K., Leppanen, A. S., Xu, C., Pitkanen, L., Eronen, P., Osterberg, M., et al. (2012). Functional and anionic cellulose-interacting polymers by selective chemo-enzymatic carboxylation of galactose-containing polysaccharides. Biomacromolecules, 13, 2418-2428.

Peng, Y. C., Gardner, D. J., \& Han, Y. S. (2012). Drying cellulose nanofibrils: In search of a suitable method. Cellulose, 19(1), 91-102.

Pereira, J. M., Mahoney, M., \& Edgar, K. J. (2014). Synthesis of amphiphilic 6-carboxypullulan ethers. Carbohydrate Polymers, 100, 65-73.

Petkowicz, C. L. O., Reicher, F., \& Mazeau, K. (1998). Conformational analysis ofgalactomannans: From oligomeric segments to polymeric chains. Carbohydrate Polymers, 37, 25-39.

Pierre, G., Salah, R., Gardarin, C., Traikia, M., Petit, E., Delort, A. M., et al. (2013). Enzymatic degradation and bioactivity evaluation of C-6 oxidized chitosan. International Journal of Biological Macromolecules, 60, 383-392.

Pridz, K. (2015). Determinants of glycosaminoglycan (GAG) structure. Biomolecules 5, 2003-2022.

Recupero, F., \& Punta, C. (2007). Free radical functionalization of organic compounds catalyzed by $N$-hydroxyphthalimide. Chemical Reviews, 107 , 3800-3842.

Rohaizu, R., \& Wanrosli, W. D. (2017). Sono-assisted TEMPO oxidation of oil palm lignocellulosic biomass for isolation of nanocrystalline cellulose. Ultrasonics Sonochemistry, 34, 631-639.

Rossi, B., Campia, P., Merlini, L., Brasca, M., Pastori, N., Farris, S., et al. (2016). An aerogel obtained from chemo-enzymatically oxidized fenugreek galactomannans as a versatile delivery system. Carbohydrate Polymers, 144, 353-361.

Saito, T., \& Isogai, A. V. (2004). TEMPO-mediated oxidation of native cellulose. The effect of oxidation conditions on chemical and crystal structures of the water-insoluble fractions. Biomacromolecules, 5, 1983-1989.

Saito, T., Yanagisawa, M., \& Isogai, A. (2005). TEMPO-mediated oxidation of native cellulose: SEC-MALLS analysis of water-soluble and -insoluble fractions in the oxidized products. Cellulose, 12, 305-315.

Sakakibara, C. N., Sierakowski, M. R., Lucyszyn, N., \& de Freitas, R. A. (2016). TEMPO-mediated oxidation on galactomannan: Gal/Man ratio and chain flexibility dependence. Carbohydrate Polymers, 153, 371-378.

Semmelhack, M. F., Schmid, C. R., Cortes, D. A., \& Chou, C. S. (1984). Oxidation of alcohols to aldehydes with oxygen and cupric ion, mediated by nitrosonium ion. Journal of American Chemical Society, 106, 3374-3376.

Semmelhack, M. F., Schmid, C. R., \& Cortés, D. A. (1986). Mechanism of the oxidation of alcohols by 2,2,6,6-tetramethylpiperidine nitrosonium cation. Tetrahedron Letters, 27(10), 1119-1122.

Sheldon, R. A., \& Arenas, I. W. C. E. (2004). Organocatalytic oxidations mediated by nitroxyl radicals. Advanced Synthesis and Catalysis, 346(9-10), 1051-1071.

Sheldon, R. A. (2007). Oxidations. In U. M. Lindstrom (Ed.), Organic reactions in water: Principles, strategies and applications (pp. 215-235). Oxford: Wiley-Blackwell.

Sheldon, R. A. (2013). Green catalytic oxidations in water. Metal-Catalyzed Reactions in Water, 139-172.

Shen, F., Zhu, H., Luo, W., Wan, J., Zhou, L., Dai, J., et al. (2015). Chemically crushed wood cellulose fiber towards high-performance sodium-ion batteries. Applied Materials and Interfaces, 7, 23291-23296.

Shi, M., Bai, J., Zhao, L., Yu, X., Liang, J., Liu, Y., et al. (2017). Co-loading and intestine-specific delivery of multiple antioxidants in $\mathrm{pH}$-responsive microspheres based on TEMPO-oxidized polysaccharides. Carbohydrate Polymers, $157,858-865$.

Sierakowski, M. R., Milas, M., Desbrières, J., \& Rinaudo, M. (2000). Specific modifications of galactomannans. Carbohydrate Polymers, 42, 51-57.

Sierakowski, M. R., Freitas, R. A., Fujimoto, J., \& Petri, D. F. S. (2002). Adsorption behavior of oxidized galactomannans onto amino-terminated surfaces and their interaction with bovine serum albumin. Carbohydrate Polymers, 49, $167-175$.
Song, X., \& Hubbe, M. A. (2014). TEMPO-mediated oxidation of oat $\beta$-D-glucan and its influences on paper properties. Carbohydrate Polymers, 99, 617-623.

Soni, B., Hassan, E. B., Shilling, M. W., \& Mahmoud, B. (2016). Transparent bionanocomposite films based on chitosan and TEMPO-oxidized cellulose nanofibers with enhanced mechanical andbarrier properties. Carbohydrate Polymers, 151, 779-789.

Souza, C. F., Lucyszyn, N., Ferraz, F., \& Sierakowski, M. R. (2011). Oxidation and $\mathrm{N}$-alkylation at the C-6 position of galactomannan extracted from Caesalpinia ferrea var. ferrea seeds. Macromolecular Symposia, 299/300, 66-73.

Spatareanu, A., Bercea, M., Budtova, T., Harabagiu, V., Sacarescu, L., Coseri, S., et al. (2014). Synthesis, characterization and solution behavior of oxidized pullulan. Carbohydrate Polymers, 111, 63-71

Stilwell, R. L., Marks, M. G., Saferstein, L., \& Wiseman, D. M. (1997). Oxidized cellulose: Chemistry, processing and medical applications. Drug Target Recovery Handbook of Biodegradable Polymers, 7, 291-306.

Su, Y., Chu, B., Gao, Y., Wu, C., Zhang, L., Chen, P., et al. (2013). Modification of agarose with carboxylation and grafting dopamine for promotion of its cell-adhesiveness. Carbohydrate Polymers, 92, 2245-2251.

Sundar Raj, A. A., Rubila, S., Jayabalan, R., \& Ranganathan, T. V. (2012). A review on pectin: Chemistry due to general properties of pectin and its pharmaceutical uses. Open Access Scientific Reports, 1(550), 1-4. http://dx.doi.org/10.4172/ scientificreports.550

Takeda, T., Miller, J. C., \& Fry, S. C. (2008). Anionic derivatives of xyloglycan funbction as acceptor but not donor substrates for xyloglucan endotransglucosylase activity. Planta, 227, 893-905.

Tamura, N., Wada, M., \& Isogai, A. (2009). TEMPO-mediated oxidation of $(1 \rightarrow 3)-\beta-D-g l u c a n s$. Carbohydrate Polymers, 77.

Tamura, N., Hirota, M., Saito, T., \& Isogai, A. (2010). Oxidation of curdlan and other polysaccharides by 4 -acetamide-TEMPO $/ \mathrm{NaClO} / \mathrm{NaClO}_{2}$ under acid conditions. Carbohydrate Polymers, 81, 592-598.

Tavernier, M. L., Delattre, C., Petit, E., \& Michaud, P. (2008). $\beta$-(1, 4)-polyglucuronic acids-An overview. The Open Biotechnology Journal, 2, 73-86.

Thaburet, J.-F., Merbouh, N., Ibert, M., Marsais, F., \& Queguiner, G. (2001). TEMPO-mediated oxidation of maltodextrins and d-glucose: Effect of pH on the selectivity and sequestering ability of the resulting polycarboxylates. Carbohydrate Research, 330, 21-29.

Viikari, L., Buchert, J., \& Kruus, K. (1999). WO Patent 99/23117.

Viikari, L., Niku-Paavola, M. L., Buchert, J., Forssell, P., Teleman, A., \& Kruus, K. (1999). WO Patent 99/23240.

Vogler, T., \& Studer, A. (2008). Applications of TEMPO in synthesis. Synthesis, 13, 1979-1993.

Wang, S., Chen, Y., Liang, H., Chen, Y., Shi, M., Wu, J., et al. (2015). Intestine-specific delivery of hydrophobic bioactives from oxidized starch microspheres with an enhanced stability. Journal of Agricultural and Food Chemistry, 63, 8669-8675.

Wang, H., Wen, F., Chen, Y., Sun, T., Meng, Y., \& Zhang, Y. (2016). Electrocatalytic determination of nitrite based on straw cellulose/molybdenum sulfide nanocomposite. Biosensors and Bioeletronics, 85, 682-687.

Watanabe, E., Habu, N., \& Isogai, A. (2013). Biodegradation of $(1 \rightarrow 3)$ - $\beta$-polyglucuronate prepared by TEMPO-mediated oxidation. Carbohydrate Polymers, 96, 314-319.

Wei, J., Chen, Y., Liu, H., Du, C., Yu, H., \& Zhou, Z. (2016). Thermo-responsive and compression properties of TEMPO-oxidized cellulose nanofiber-modified PNIPAm hydrogels. Carbohydrate Polymers, 147, 201-207.

Weishaupt, R., Siqueira, G., Schubert, M., Tingaut, P., Maniura-Weber, K., Zimmermann, T., et al. (2015). TEMPO-oxidized nanofibrillated cellulose as a high density carrier for bioactive molecules. Bioomacromolecules, 16, 3640-3650.

Yackel, E. A., \& Kenyon, W. O. (1942). The oxidation of cellulose by nitrogen dioxide. Journal of the American Chemical Society, 64, 121-127.

Yoo, S.-H., Lee, J.-S., Park, S. Y., Kim, Y.-S., Chang, P.-S., \& Lee, H. G. (2005). Effects of selective oxidation of chitosan on physical and biological properties. International Journal of Biological Macromolecules, 35, 27-31.

Zhang, K., Peschel, D., Klinger, T., Gebauer, K., Groth, T., \& Fischer, S. (2010). Synthesis of carboxyl cellulose sulfate with various contents of regioselectively introduced sulfate and carboxyl groups. Carbohydrate Polymers, 82, 92-99.

Zhang, X., Wang, Y., Zhao, J., Xiao, M., Zhang, W., \& Lu, C. (2016). Mechanically strong and thermally responsive cellulose nanofibers/poly( $\mathrm{N}$-isopropylacrylamide) composite aerogels. ACS Sustainable Chemistry and Engineering, 4, 4321-4327.

Zhang, N., Zang, G.-L., Shi, C., Yu, H.-Q., \& Sheng, G.-P. (2016). A novel adsorbent TEMPO-mediated oxidized cellulose nanofibrils modified with PEI: Preparation, characterization, and application for $\mathrm{Cu}(\mathrm{II})$ removal. Journal of Hazardous Materials, 316, 11-18

Zhao, Y., Zhang, Y., Lindström, M. E., \& Jiebing, L. (2015). Tunicate cellulose nanocrystals: Preparation, neat films and nanocomposite films with glucomannans. Carbohydrate Polymers, 117, 286-296. 